\title{
Affective neuroscience of pleasure: reward in humans and animals
}

\author{
Kent C. Berridge $\cdot$ Morten L. Kringelbach
}

Received: 3 July 2007 / Accepted: 31 January 2008 /Published online: 3 March 2008

(C) Springer-Verlag 2008

\begin{abstract}
Introduction Pleasure and reward are generated by brain circuits that are largely shared between humans and other animals.

Discussion Here, we survey some fundamental topics regarding pleasure mechanisms and explicitly compare humans and animals.

Conclusion Topics surveyed include liking, wanting, and learning components of reward; brain coding versus brain causing of reward; subjective pleasure versus objective hedonic reactions; roles of orbitofrontal cortex and related cortex regions; subcortical hedonic hotspots for pleasure generation; reappraisals of dopamine and pleasure-electrode controversies; and the relation of pleasure to happiness.
\end{abstract}

Keywords Reward $\cdot$ Pleasure $\cdot$ Motivation $\cdot$ Hedonic . Food $\cdot$ Addiction $\cdot$ Nucleus accumbens .

Orbitofrontal cortex · Opioid · Dopamine - Mesolimbic .

Deep brain stimulation - Addiction

K. C. Berridge $(\bowtie)$

Department of Psychology, University of Michigan,

Ann Arbor, MI, USA

e-mail: berridge@umich.edu

M. L. Kringelbach ( $\square)$

Department of Psychiatry, Warneford Hospital,

University of Oxford,

Oxford, UK

e-mail: Morten.Kringelbach@queens.ox.ac.uk

M. L. Kringelbach

Centre for Functionally Integrative Neuroscience (CFIN),

University of Aarhus,

Aarhus, Denmark

\section{Introduction}

Affective neuroscience has emerged as an exciting discipline in recent years (Berridge 2003a; Damasio 2004; Davidson et al. 2003; Davidson and Sutton 1995; Feldman Barrett and Wager 2006; Kringelbach 2005, 2008; LeDoux and Phelps 2000; Leknes and Tracey 2008; Panksepp 1991; 1998; Rolls 2005). Many important insights have been gained into brain mechanisms of affect, motivation, and emotion through studies of both animals and humans.

A particularly important topic for affective neuroscience is to understand how brains generate pleasure and other psychological components of reward because reward is important in daily life. Pleasure is essential to a normal sense of well-being. Pathological losses of pleasure may be a devastating part of many affective disorders ranging from depression to schizophrenia and addiction.

Here, our aim is to bridge findings from research in humans and other animals on pleasure and reward (Kringelbach and Berridge 2008). In this review, we hope to explore some of the principles important for a general understanding of how the brain mediates pleasure. Such principles may have important translational implications for treating affective disorders. Finally, to help clarify the discussion, we have included a glossary of terms at end.

\section{Multiple psychological components of reward}

We note that a pleasant stimulus is often called a rewarding stimulus or simply a reward. However, it is useful to keep in mind that actual reward lies in active processes of the brain and mind that reacts to a stimulus rather than the stimulus itself. Further, reward may appear at first glance to be a unitary process, but it is actually a composite or 
complex process containing several psychological components that correspond to distinguishable neurobiological mechanisms (Berridge and Robinson 2003; Dickinson and Balleine 2002; Everitt and Robbins 2005; Kelley et al. 2005; Kringelbach 2005; Kringelbach and Berridge 2008; Leknes and Tracey 2008; Schultz 2006). The major components of reward and their subdivisions include:

Liking: the actual pleasure component or hedonic impact of a reward. Pleasure comprises two levels: (1) core 'liking' reactions that need not necessarily be conscious; (2) conscious experiences of pleasure, in the ordinary sense of the word, which may be elaborated out of core 'liking' reactions by cognitive brain mechanisms of awareness (see "A glossary of reward definitions" below for more detail on definitions).

Wanting: motivation for reward, which includes both (1) incentive salience 'wanting' processes that are not necessarily conscious and (2) conscious desires for incentives or cognitive goals.

Learning: associations, representations, and predictions about future rewards based on past experiences. Learned predictions include both (1) explicit and cognitive predictions and (2) implicit knowledge as well as associative conditioning, such as basic Pavlovian and instrumental associations.

Extensive research has demonstrated that these different psychological components are mediated by partly dissociable brain substrates. Within each reward component, there are further subdivisions and levels, including both conscious and non-conscious processing. The existence of multiple types of components within reward provides challenges as well as opportunities to affective neuroscientists. The primary challenge is to identify which brain systems mediate pleasure versus other components of reward and to map components correctly onto their own neural substrates (Fig. 1). This challenge is difficult because a rewarding stimulus or event will elicit many or all of these reward components simultaneously and so activate many brain systems at the same time. Careful studies are needed to tease apart whether activity in a particular brain region belongs most to the 'liking', 'wanting', or learning sub-components of reward and to understand how components are assembled by larger limbic circuits into an integrated reward system (Baldo and Kelley 2007; Balleine and Killcross 2006; Beaver et al. 2006; Burke et al. 2008; Di Chiara and Bassareo 2007; Evans et al. 2006; Everitt and Robbins 2005; Izard 2007; Koob and Le Moal 2006; Kringelbach 2004; Leyton et al. 2005; Panksepp 2007; Salamone et al. 2007; Schultz 2006; Volkow et al. 2006; Wise 2006).

An opportunity arises from this for basic neuroscientists to provide a richer reality for understanding how different brain systems play distinct roles in the composite of reward. Applied to psychopathology, this has important implications for understanding how a particular brain dysfunction might generate its distinct pattern of psychological disorder, which, in turn, may create novel opportunities for clinical neuroscientists to move beyond 'one size fits all' therapeutic strategies and to better allow the design of particular therapies to reverse or compensate for particular types of psychopathological dysfunction.

Of the three types of reward component, pleasure or hedonic 'liking' has probably been the least addressed in neuroscience studies. There is a special need for better understanding of how pleasure is generated by brain systems, and so we will focus particularly on pleasure in this paper.

Fig. 1 Hedonic hotspots and hedonic circuits. Hedonic hotspots are shown in nucleus accumbens, ventral pallidum, and brainstem parabrachial nucleus where opioid or other signals cause amplification of core 'liking' reactions to sweetness. Reprinted with permission from Smith et al. (2008), based on Kringelbach (2005), Peciña et al. (2006), and Smith and Berridge (2007)

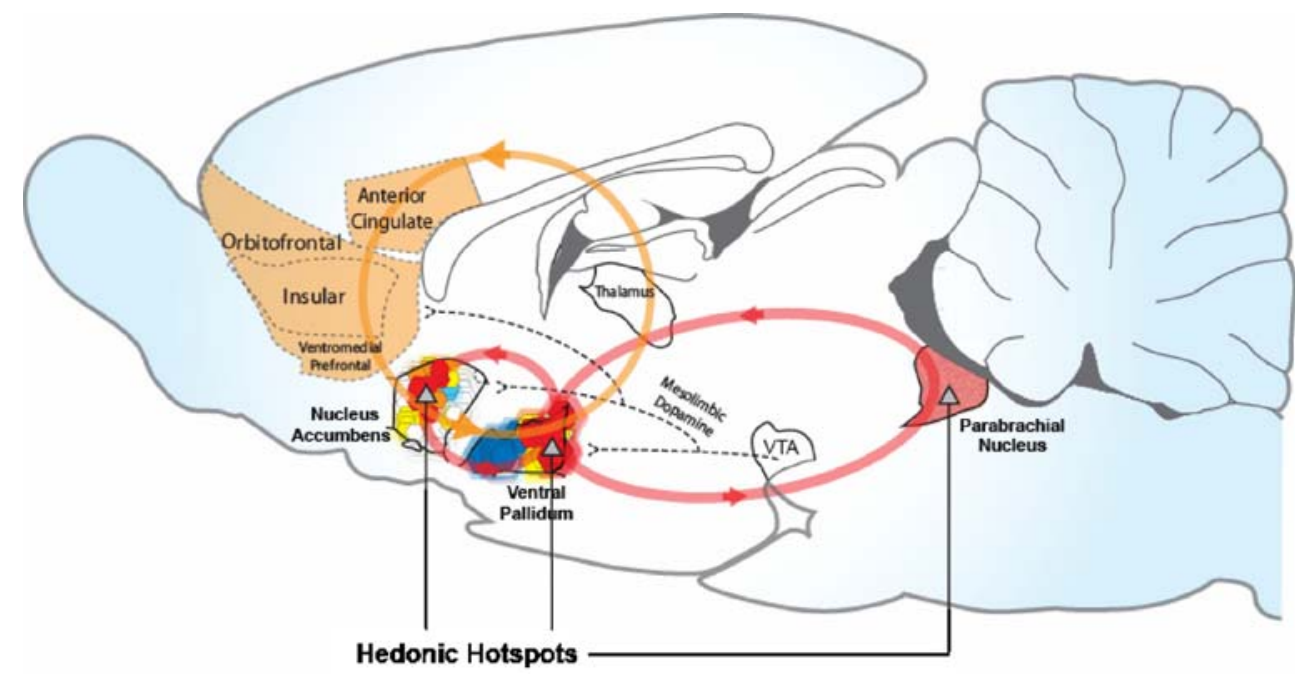




\section{From sensation to pleasure}

Pleasure is never merely a sensation (Frijda 2007; Kringelbach and Berridge 2008; Ryle 1954). Instead, it always requires the activity of hedonic brain systems to paint an additional "hedonic gloss" onto a sensation to make it 'liked'. That is consistent with the role of pleasure in the valuation of sensory stimuli in decision making, including most importantly their hedonic valence, in order to act as an interface between sensation and goal-directed action (Dickinson and Balleine 2008). Pleasure here is defined as a 'liking' reaction to reward, whether explicitly felt in consciousness or not. It comprises the positive dimension of the more general category of hedonic processing important to survival, which also includes other negative and unpleasant dimensions such as pain. Pleasure conceptualized in this way may well be present in many animal species besides humans.

Some stimuli are more likely to elicit pleasure than others - to be painted with a hedonic gloss. Since pleasure must ultimately serve a central role in fulfilling Darwinian imperatives of survival and procreation, the sensory pleasures linked to food intake as well as sex are likely to be fundamentally basic (Cabanac 1992, 2008; Darwin 1872; Kringelbach 2008; Nesse 2002; Panksepp 1998; Rolls 2005; Schulkin 2004).

Food is one of the most universal routes to pleasure and is one of the most accessible experimental methods available to neuroscience studies of pleasure (Kringelbach 2005; Peciña et al. 2006; Rozin 1999; Small et al. 2001). The two most important senses involved in food intake are smell and taste, which must interact to facilitate human decision making and hedonic experience (Gottfried 2008; Small and Veldhuizen 2008). Four computational principles have been proposed for the interaction between sensory and hedonic processing in humans and other primates: (1) motivation-independent processing of identity and intensity, (2) formation of learning-dependent multimodal sensory representations, (3) reward representations using statedependent mechanisms including selective satiation, and (4) representations of hedonic experience, monitoring/ learning, or direct behavioral change (Kringelbach 2005). Beyond food, sex is another potent natural pleasure, and some other special classes of stimuli also appear to be important, though more subtle. Drugs of abuse that act as rewards are widely viewed to usurp the brain systems that evolved to mediate sensory pleasures such as food and sex. Social interactions with conspecifics are important to the propagation of genes in all social animals such as humans, which means that social pleasures are also likely to be part of the repertoire of fundamental pleasures. Social pleasures in animals other than humans might be conceived as essentially similar to basic sensory pleasures or conceivably even in some nonhuman species as something more abstract. Social pleasures include sensory visual features such as faces, touch features of grooming and caress, as well as in humans more abstract and cognitive features of social reward. In particular, adult pair bonds and attachment bonds between parents and infants are likely to be extremely important. In fact, it might well be that in humans at least, the social pleasures are perhaps as pleasurable as the basic sensory pleasures.

In addition to these basic sensory and social pleasures, there are a large number of higher-order pleasures that are prominent in humans, including monetary, artistic, musical, altruistic, and transcendent pleasures. Such higherorder pleasures depend on learning and might be conceptualized as higher-dimensional combinations of the basic pleasures, and as such may re-use some of the same brain mechanisms.

\section{Is human pleasure similar or different to that of other animals?}

Pleasure and displeasure reactions are prominent in our own lives and in the behavior of many other animals and may have had similar evolutionary functions in common ancestors of both (Fig. 2). The underlying limbic neural mechanisms for generating affective reactions are well developed and similar in the brains of most mammals (at least). It seems unlikely that so much neural machinery would have been selected and conserved across species if it had no function. Basic core pleasure reactions have always had objective consequences for an individual's behavior, physiology, and eventual gene fitness, and brain mechanisms for those hedonic reactions could have evolved well before the additional mechanisms needed for human subjective feelings of pleasure. In a sense, hedonic reactions have been too important to survival for hedonia to be exclusively subjective. Common function and neural conservation of machinery suggest that pleasure may be similar across humans and many animals.

For pleasure feelings, specialized, though elusive, brain mechanisms of conscious elaboration are likely needed to convert an objective 'liking' reaction to a hedonic stimulus into a subjectively felt liking experience. Thus, it may well be that human conscious experience of pleasure is different not only quantitatively but also qualitatively from other animals. Human cognitive capacity transforms and elaborates our mental representations of pleasant events, adding richness and the capacity to savor by altering the attention we pay and the way we think about pleasures (Barrett et al. 2007a, b; Frijda 2007; Frijda and Sundararajan 2007; Gilbert and Wilson 2007; Higgins 2006). Cognition also vastly expands the range of events that can trigger pleasure 


\section{Opioid 'liking' and 'wanting' zones in NAc shell}
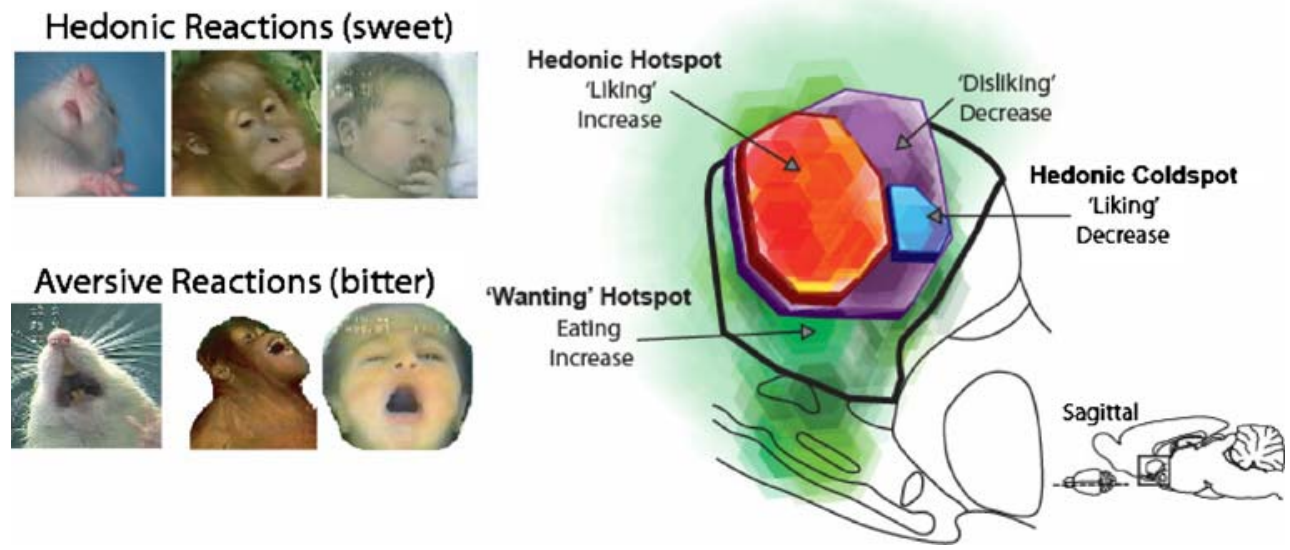

Fig. 2 Taste 'liking' reactions and contrast map of nucleus accumbens hotspots. Positive 'liking' reactions to pleasant sweet tastes shared by human newborn, young orangutan, and adult rat (tongue protrusion, left top) and aversive 'disliking' reactions to unpleasant bitter tastes (gape, left bottom). Opioid hotspots and coldspots in the nucleus accumbens (medial shell region shown in sagittal view, right). Green The entire medial shell mediates opioid-stimulated increases in

in humans to include cognitive and cultural sources (art, music, dinner parties and as well as other social, intellectual and aesthetic rewards) and provides new top-down regulatory ways to amplify or dampen a pleasure or displeasure.

Conclusions about brain reward systems derived from animal studies versus human studies typically produce conclusions that are similar and complementary, at least for mechanisms of core pleasure reactions, and below we will focus on brain issues that are mostly shared across humans and animals.

\section{Pleasure coding versus causality}

The occurrence of pleasure is coded by neural activity in many brain sites, including orbitofrontal cortex, anterior cingulate cortex, insular cortex, amygdala, nucleus accumbens and related striatum, ventral pallidum, and brainstem sites including mesolimbic dopamine projections (Berns et al. 2001; Blood and Zatorre 2001; Cardinal et al. 2002; Everitt and Robbins 2005; Kringelbach 2004, 2005; Kringelbach and Berridge 2008; Kringelbach et al. 2004; Levine et al. 2003; Menon and Levitin 2005; O'Doherty et al. 2002; Pelchat et al. 2004; Rolls 2005; Schultz 2006; Small et al. 2001; Volkow et al. 2002; Wang et al. 2004; Watson et al. 2006; Figs. 1, 2 and 3).

But do all brain structures that code for pleasure actually help to cause it? A useful distinction can be made between coding and causing pleasure in the brain, where the former method can reflect not only pleasure causation but also brain activity that results from pleasure enhancement but causes another function, whereas the latter method is 'wanting' for food reward. Red Only a cubic-millimeter-sized hedonic hotspot generates increases in 'liking' for the same opioid stimulation. Blue A small hedonic 'coldspot' suppresses 'liking' reactions to sucrose, whereas a larger purple zone suppresses 'disliking' reactions to quinine. Reprinted with permission from Smith et al. (2008), based on data from Peciña and Berridge (2005)

related only to activity that enhances pleasure reactions as its consequence. This implies that some brain activations may both cause and code pleasure reactions, whereas others do not cause pleasure but may code it while causing other psychological or behavioral changes. Neural coding is inferred in practice by measuring brain activity correlated to a pleasure, using techniques such as PET, fMRI, and magnetoencephalography (MEG) neuroimaging in humans or electrophysiological or neurochemical activation measures in animals presented with a rewarding stimulus (Figs. 3 and 4). Causation is generally inferred on the basis of a change in pleasure as a consequence of a brain manipulation such as lesion or stimulation (Figs. 1 and 2). Neural coding is sometimes meant as though it also necessarily implied causation. But the two are logically different, and some evidence indicates that the brain sometimes organizes them differently, too.

Coding and causation often go together of course, but they need not always be identical. As a general rule, it would appear that the information about the pleasure elicited by stimuli is coded by many anatomical regions and neurochemical systems but only generated by a smaller subset. The brain may thus operate by the principle of 'more codes than causes' for pleasure, resulting in part from the tendency of signals to spread beyond their source and from the need for some brain systems to translate reward signals into other psychological functions such as learning and memory, cognitive representations, decisions, action, consciousness, and so on.

Code-but-not-cause systems might nonetheless be reliable indicators that a pleasant event is occurring because they must take pleasure signals as inputs to achieve other 
Fig. 3 Valence coding in medial OFC. a The activity in medial OFC correlates with the subjective ratings of pleasantness in an experiment with three pleasant and three unpleasant odors (Rolls et al. 2003). b Similarly, the activity in medial OFC was also correlated with the subjective pleasantness ratings of water in a thirst experiment (de Araujo et al. 2003b). A correlation in a very similar part of medial OFC was found with the pleasantness of other pure tastants used in the experiment (not shown). c This corresponded to the findings in an experiment investigating taste and smell convergence and consonance, which found that activity in the medial OFC was correlated with subjective consonance ratings (de Araujo et al. 2003c). d Even higher-order rewards such as monetary reward were found to correlate with activity in the medial OFC (O'Doherty et al. 2001) a
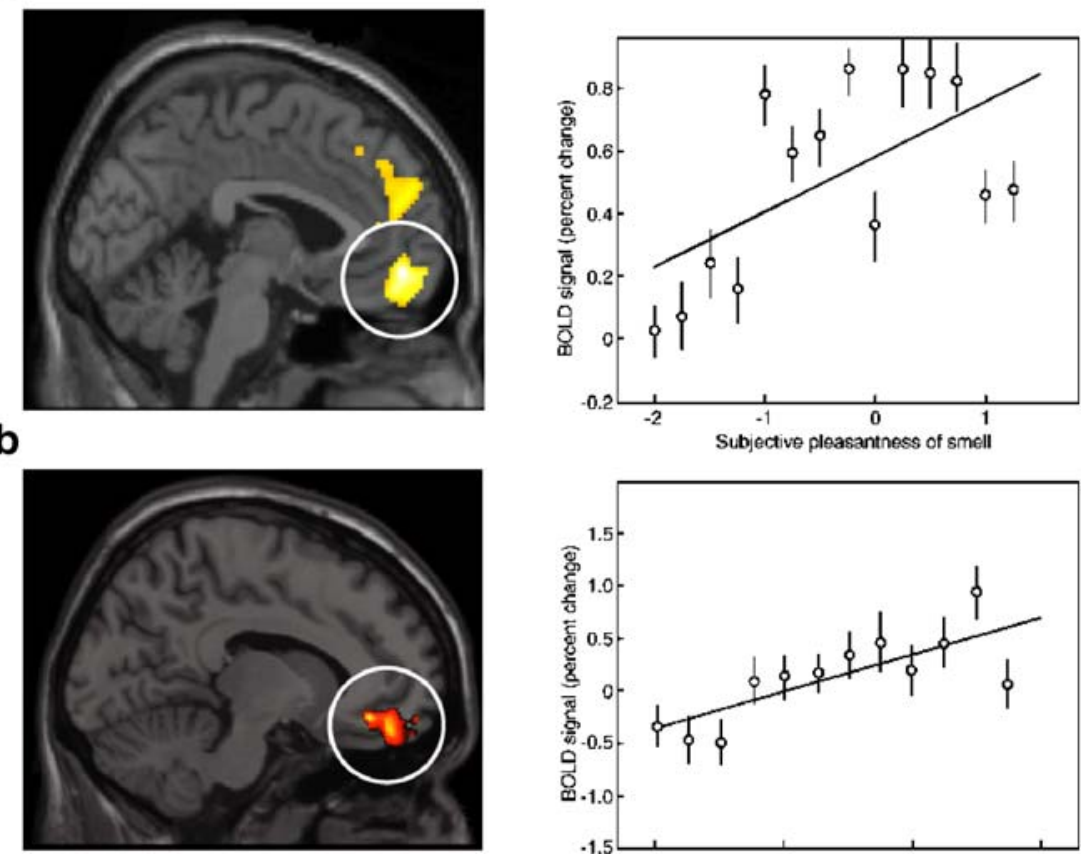

C
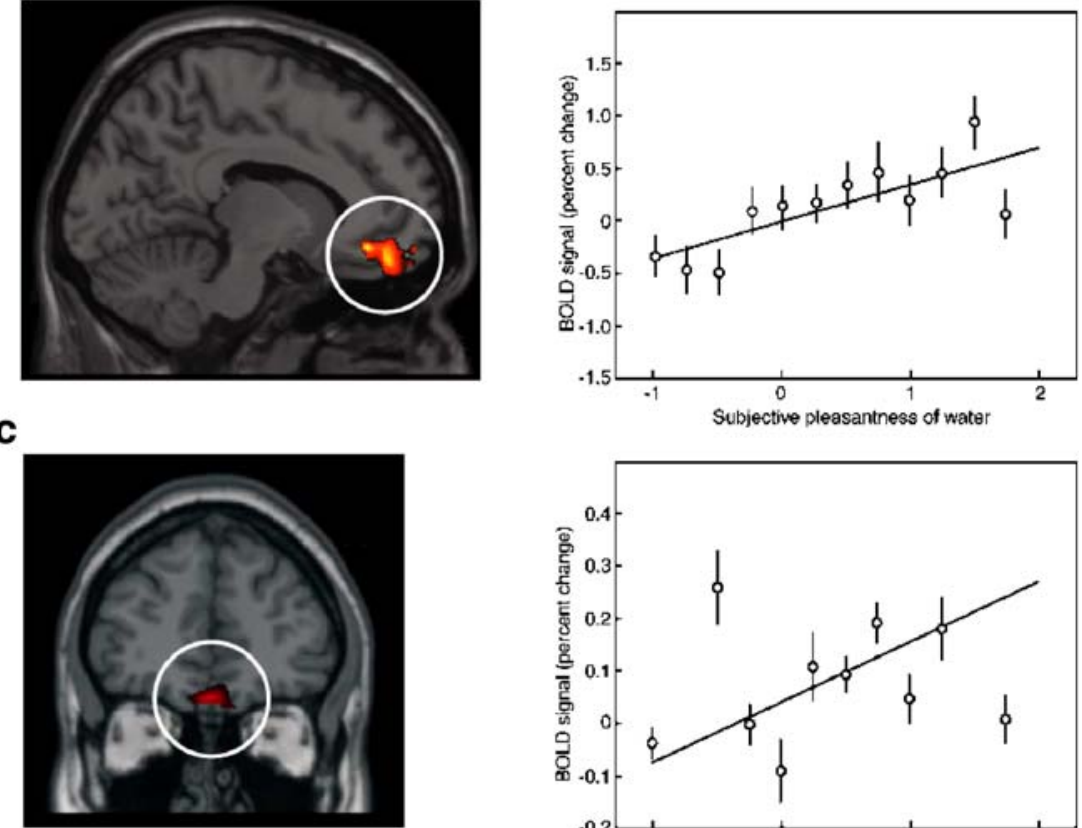

d

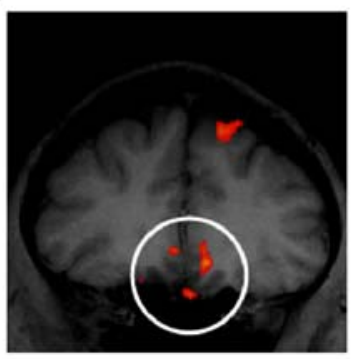

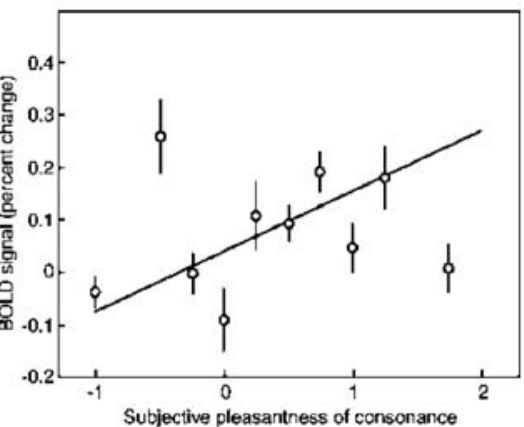

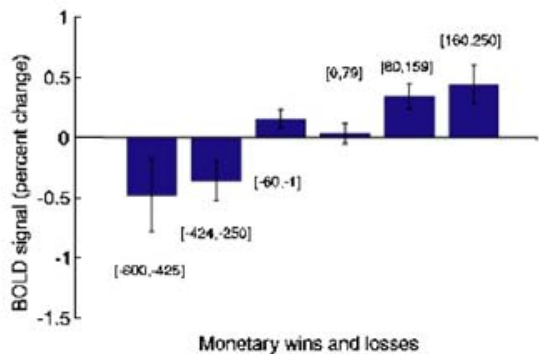

component processes in reward and related tasks (e.g., cognitive representations and memories of reward [reward learning], motivational value appraisals or decisions [reward wanting]). For example, prefrontal cortex regions sensitively code reward and hedonic impact, as described below. Yet damage to ventromedial region of prefrontal cortex may impair the cognitive use of emotional reactions without necessarily impairing the capacity to experience the hedonic impact of those emotional reactions (Bechara et al. 1997; Damasio 1999; Damasio 2004; Kringelbach 2005; Kringelbach and Berridge 2008). The difference between coding and causing poses challenges to affective neuroscience studies. How to distinguish between coding activations that cause pleasure or other reward components from other coding activations that instead cause other functions? And how to identify those other functions?

\section{On necessary and sufficient causes of pleasure}

Even within neural causation of pleasure, it may be useful to distinguish further. How to assign causal status to brain 


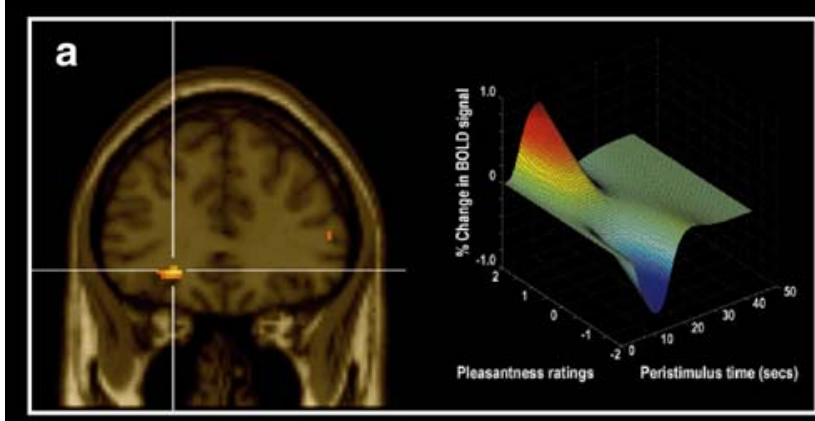

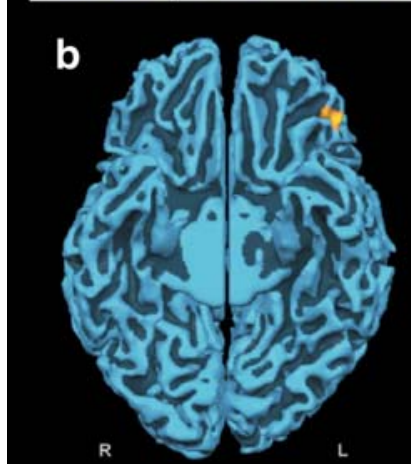
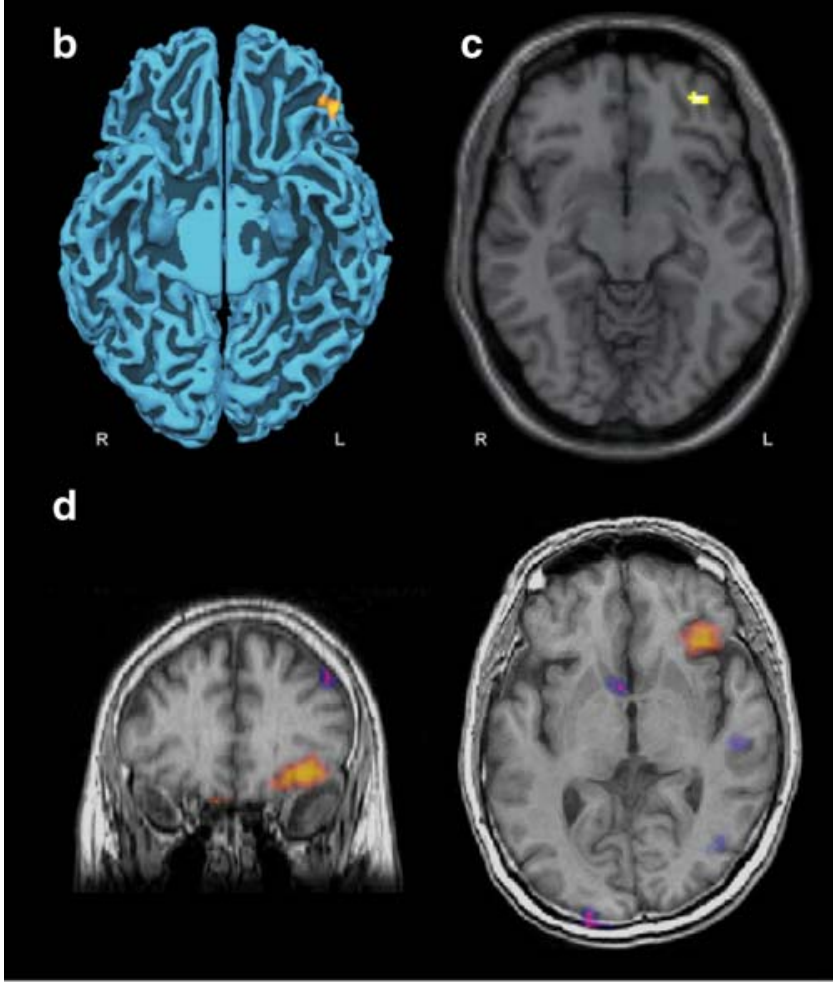

events is a complicated issue, but it is not too much an oversimplification to suggest that in practice, the causal status of brain mechanisms in reward has been approached in two distinct experimental ways. These ways correspond to the ideas of a 'necessary cause' and a 'sufficient cause'.

One experimental approach is to ask 'What reward function is lost?' when a brain system is suppressed (e.g., by antagonist drugs, lesions, genetic manipulations, or other brain manipulations). That approach asks about the brain system's role as a necessary cause for pleasure or other reward components; it identifies brain systems without which normal reward cannot be carried on. Necessary causation implies that if activity in a brain region is a necessary cause of pleasure, then the presence of a normal pleasure reaction requires the participation of this brain region. The mere presence of this neural activity does not, however, imply that pleasure will occur. In practice, necessary causation is revealed when a lesion or pharmacological suppression produces a deficit in pleasure.
Fig. 4 Hedonic experience. a The activity in mid-anterior parts of the orbitofrontal cortex correlated with the subjective pleasantness ratings of the foods (Kringelbach et al. 2003). On the right is shown the magnitude of the fitted hemodynamic response from a representative subject plotted against the subjective pleasantness ratings (on a scale from -2 to +2 ) and peristimulus time in seconds. b Additional evidence for the role of the mid-anterior orbitofrontal cortex in subjective experience comes from another neuroimaging experiment investigating the supra-additive effects of combining the umami tastants monosodium glutamate and inosine monophosphate (de Araujo et al. 2003a). The figure shows the region of mid-anterior orbitofrontal cortex showing synergistic effects (rendered on the ventral surface of human cortical areas with the cerebellum removed). The synergy is unlikely to be expressed in the taste receptors themselves, and the activity in the orbitofrontal cortex may thus reflect the subjective enhancement of umami taste, which must be closely linked to subjective experience. c Adding strawberry odor to a sucrose taste solution makes the combination more pleasant than the sum of each of the individual components. The supra-linear effects on subjective enhancement activated a lateral region of the left midanterior orbitofrontal cortex, similar to as found in other experiments (de Araujo et al. 2003c). d These findings were strengthened by findings using DBS and MEG (Kringelbach et al. 2007a). Pleasurable subjective pain relief for chronic pain in a phantom limb in a patient was causally induced by effective deep brain stimulation in the PVG/ PAG part of the brainstem. When using MEG to directly measure the concomitant changes in the rest of the brain, a significant change in power was found in the mid-anterior $\mathrm{OFC}$

A different approach is to ask 'What reward function is enhanced?' by activation of a brain system. That approach asks about the brain system's role as a sufficient cause for increases in pleasure or another reward component (when other conditions in the brain do not simultaneously change so much as to invalidate hopes of obtaining a specific answer). This enhancement approach uses agonist drugs, brain stimulation, or other means to stimulate neural activity and asks if reward occurs or becomes magnified above normal levels as a consequence. Sufficient causation implies that if activity in a brain region is a sufficient cause of pleasure, then activation of this brain region will result in enhanced pleasure reactions (however, multiple brain mechanisms might participate in parallel, and so the presence of a pleasure reaction need not imply the neural activity in a particular location). In practice, sufficient causation is revealed when stimulation of a brain system produces an increase in a pleasure reaction.

Neuroscientists may traditionally expect the same brain system to have both roles as a necessary and a sufficient cause. That may often be true, and if so, then neural activation or inhibition of the same system should produce bidirectional changes in reward, either up or down. But necessary and sufficient causes need not always go together. In some cases, a brain system might act as a sufficient cause to elevate without being a necessary cause for normal levels of pleasure or vice versa. For example, activations in the nucleus accumbens are a sufficient cause 
to enhance several aspects of reward (Cardinal et al. 2002; Everitt and Robbins 2005; Kelley et al. 2002; Kelley et al. 2005; Koob and Le Moal 2006; Kringelbach and Berridge 2008; Peciña et al. 2006; Robbins and Everitt 2002; Salamone et al. 2007; Shizgal et al. 2001; Szczypka et al. 2001), yet damage to the nucleus accumbens may only subtly impair the hedonic impact or related components of natural rewards such as food (Balleine and Killcross 1994; Parkinson et al. 1999; Setlow et al. 2002; Whishaw and Kornelsen 1993). Core 'liking' reactions to pleasure may be relatively difficult to abolish absolutely by a single brain lesion or drug, which may be very good in evolutionary terms. An important task for affective neuroscience is to identify the few substrates that are really necessary for normal pleasure (and relate them to those that enhance pleasure above normal).

\section{The consciousness of pleasure: can 'liking' ever be unconscious?}

Pleasure has often been defined as the conscious experience of reward, but it is questionable whether such a narrow definition is the most meaningful or useful in the end. An expanded definition may be more useful for neuroscientists when dealing with pleasure. Perhaps surprisingly, the act of engaging in conscious introspection about pleasure does not always improve the quality of its capture (Dijksterhuis et al. 2006; Gilbert 2006; Schooler and Mauss 2008). For example, when people introspect extensively about why they prefer a reward stimulus such as one fruit-spread, painting, or car over another, they may often end up more confused about their underlying preferences than when they simply make snap judgments about the same choices (Schooler and Mauss 2008). Much of our brain activity is not available for conscious introspection, and neuroscientific evidence from humans and other animals has made it clear that non-conscious brain activity is essential for controlling our behavior. Some of this non-conscious brain activity is related to hedonic processing and may lead to hedonic reactions.

Also surprising by the traditional definition, hedonic reactions themselves can actually even be non-conscious. For example, non-conscious pleasure in the form of 'liking' and 'wanting' without subjective awareness of their occurrence has been produced in ordinary people (Winkielman et al. 2005). In those people, consumption behavior was altered by subliminal exposure to happy/angry facial expressions, which changed their desire to drink a subsequently encountered beverage and their ratings of its value, even though they felt no conscious emotional reactions at all at the moment their affective reaction was subliminally caused. Subliminal emotional expressions likewise have been reported to alter ongoing instrumental tasks to win money and simultaneously activate brain reward structures such as ventral pallidum and amygdala regardless of whether or not the facial expressions are perceived consciously (Pessiglione et al. 2007; Whalen et al. 1998). Similarly, human drug addicts may work to self-administer drugs even under particular conditions where the low doses available apparently produce no subjective effects or autonomic reaction (Fischman and Foltin 1992; Hart et al. 2001; Lamb et al. 1991).

We would not suggest that all instances of behavioral positive reinforcement necessarily entail pleasure, whether conscious or non-conscious. But there is enough evidence to seriously entertain the hypothesis that the human brain can generate a positive hedonic 'liking' reaction of which the introspecting mind remains unaware. In a similar way to how it is has proven useful to divide emotion into the nonconscious and conscious sub-components of emotions and feelings, we do suggest it might be more useful and meaningful to divide pleasure into both non-conscious (core 'liking') and conscious (subjective liking) subcomponents of evaluative hedonic processing. Such a definition would hold that while pleasure plays a central role for emotions and conscious feelings, it is not itself a conscious feeling. This definition also paves the way for affective neuroscience studies of animals to help provide insights into neural mechanisms underlying core 'liking' reactions by avoiding obstructions arising from uncertainty about criteria for consciousness.

Measuring objective as well as subjective pleasure

Pleasure has manifestations both in consciousness (subjective liking) and in brain and behavioral reactions (objective 'liking'). Objective reactions to pleasure in both humans and animals have been used as an additional handle by neuroscientists and psychologists in their efforts to gain scientific purchase on pleasure.

While the pleasure of a reward such as sweetness can be measured by verbal reports in conscious humans, this hedonic processing is not dependent on the presence of language. In most non-linguistic mammals, pleasure will also elicit affective 'liking' reactions, reflecting in a basic form the hedonic gloss to the sensation, which we experience as conscious pleasure (Berridge 2000; Kringelbach 2008; Peciña et al. 2006).

One strategy used to find neural generators of pleasure such as brain hedonic hotspots relies on finding examples of useful 'liking' reactions. One such example is the affective facial expression elicited by the hedonic impact of sweet tastes in newborn human infants (Fig. 2). Sweet tastes elicit positive facial 'liking' expressions (tongue protrusions, etc.), whereas bitter tastes instead elicit facial 
'disliking' expressions (gapes, etc.). These homologousaffective expressions (sharing features such as identical allometric timing laws) seem to have developed from the same evolutionary source in humans, orangutans, chimpanzees, monkeys, and even rats and mice (Grill and Norgren 1978a; Steiner 1973; Steiner et al. 2001). Homology in origin of 'liking' reactions implies that the underlying hedonic brain mechanisms are similar in humans and other animals, opening the way for an affective neuroscience of pleasure that bridges both.

\section{Pleasure generators: hedonic hotspots in the brain}

What brain systems paint a hedonic gloss onto mere sensation? The brain appears frugal in mechanisms that that are sufficient cause to generate or magnify pleasure. Compelling evidence for pleasure causation as increases in 'liking' reactions has so far been found for only a few subcortical brain substrates or hedonic hotspots.

Subcortical hedonic hotspots in nucleus accumbens, ventral pallidum, and brainstem

For example, affective neuroscience studies of rodents have indicated pleasure 'liking' reactions to be coordinated by a network of hedonic hotspots distributed across the brain. Each hotspot may be merely a cubic millimeter or so in volume in the rodent brain (and should be a cubic centimeter or so in humans, if proportional to whole brain volume) and is capable of generating enhancements of 'liking' reactions to a sensory pleasure such as sweetness, when opioid, endocannabinoid, or other neurochemical receptors within it are stimulated (Mahler et al. 2007; Peciña and Berridge 2005; Peciña et al. 2006; Smith and Berridge 2005; Smith et al. 2008). Anatomical hotspot coding indicates a surprisingly high degree of localization of function for sufficient-cause pleasure mechanisms in the brain, and hotspot segregation within a limbic structure might provide a way for opioid or related brain signals to disambiguate pleasure versus pain via localization of function if the same neurochemical signal mediates both types of valence (Petrovic 2008; Reynolds and Berridge 2002; Scott et al. 2007; Smith et al. 2008; Wager et al. 2004; Wightman et al. 2007).

Hotspots exist in nucleus accumbens shell, ventral pallidum, and possibly other forebrain and limbic cortical regions and also deep brainstem regions including the parabrachial nucleus in the pons (Figs. 1 and 2). Microinjections of drugs that activate neuronal opioid, endocannabinoid, or related neurochemical receptors in these hedonic hotspots (e.g., rostral-dorsal quadrant of nucleus accumbens shell; posterior half of ventral pallidum) may double or triple the normal number of 'liking' reactions to a sucrose taste (Mahler et al. 2007; Peciña and Berridge 2005; Smith and Berridge 2005; Smith et al. 2008). Analogous to scattered islands that form a single archipelago, distributed hedonic hotspots form functional integrated circuits, which obey control rules that are largely hierarchical and organized into brain levels (Grill and Norgren 1978b; Peciña et al. 2006). Top levels contain accumbenspallidal hotspots that function together as a cooperative heterarchy, so that, for example, enhancing 'liking' above normal by opioid stimulation may require unanimous 'votes' in favor from more than one participating hotspot in the forebrain (Smith and Berridge 2007; Smith et al. 2008).

Of course, objective evidence for 'liking' enhancement needs special scrutiny to ensure that a brain activation does not merely cause something simpler, such as general arousal. Several observations lean against simpler interpretations for limbic hedonic hotspots. For example, enhanced 'liking' reactions are not amplified 'in vacuum' as motor reactions by accumbens or pallidal activation but rather only if a palatable taste is also presented simultaneously, and always in a signature hedonic pattern of several 'liking' reactions. Hotspot enhancement of 'liking' never amplifies negative 'disliking' or neutral reactions, ruling out general activation explanations of increased hedonic reactions (Berridge 2000; Mahler et al. 2007; Peciña and Berridge 2005; Smith and Berridge 2007). Also, converging evidence comes from studies of the neuronal coding of natural pleasure enhancements within hedonic hotspots (Aldridge and Berridge 2008; Kringelbach 2005). For example, salt appetite induced by physiological sodium depletion causes sudden 'liking' of an intensely salty taste that is normally 'disliked' (triple seawater $\mathrm{NaCl}$ concentration) and simultaneously makes neurons in the ventral pallidum hotspot fire as vigorously to the salty taste as they do to sweetness (but do not similarly fire to 'disliked' salt or other stimuli; Aldridge and Berridge 2008; Tindell et al. 2006; Wheeler and Carelli 2006). Such observations tend to support the idea that when drugs in limbic hotspots enhance 'liking' reactions, the experiment has tapped into the affective generation of pleasure.

Only one hedonic hotpot so far appears to be strongly necessary to normal pleasure in the sense that damage to it abolishes and replaces 'liking' reactions to sweetness with bitter-type 'disliking' instead (e.g., gapes). That essential hotspot appears to be in the posterior ventral pallidum and perhaps adjacent areas in extended amygdala, substantia innominata, and lateral hypothalamus (Cromwell and Berridge 1993; Peciña et al. 2006; Schallert and Whishaw 1978; Stellar et al. 1979; Teitelbaum and Epstein 1962). The striking restriction of brain substrates where damage converts 'liking' to 'disliking' seems a testimonial to the 
robustness of the brain's capacity for a basic pleasure reaction (Smith et al. 2008).

\section{Cortical cognition and pleasure}

It is becoming possible to integrate pleasure, motivation, and emotion into cognitive and systems neurosciences. Some neuroscientists and psychologists have tended to see cognition as separate from pleasure, emotion, and motivation. Pleasure is essentially affective, whereas cognition is not. Cognition is essentially representative of other events or relations, whereas pleasure is not. Cognition is essential to other non-pleasure components that compose the reward process (e.g., perceiving and knowing at a distance that stimuli are positive through associative mechanisms, learning to anticipate a positive stimulus in time, space, and context, and other memory, decision and action functions mediated by brain systems beyond those that generate hedonic pleasure).

Yet more fundamentally, it is difficult to see how cognition could proceed without hedonic processes in real life. Pleasure clearly influences cognition, and cognition influences pleasure. Take the example of the human dorsolateral prefrontal cortex, which is the structure that many would point to as the main brain region involved in cognition and higher-order cognitive concepts like working memory and selection for action. The dorsolateral prefrontal cortex also has valenced representations of taste and other hedonic stimuli, which could aid higher cognitive processes in guiding complex motivational and emotional behavior (Barrett et al. 2007b; Davidson et al. 2003; Kringelbach et al. 2004; Kringelbach and Rolls 2004; Wallis and Miller 2003).

In humans, neuroimaging studies have found that the affective valence of pleasure may be coded separately from sensation intensity in a network of brain regions (Anderson and Sobel 2003; Gottfried et al. 2002; Rolls et al. 2003; Small et al. 2003). As an example, taste intensity (but not valence) was coded by anterior insula cortex activity (primary gustatory area), while subjective pleasantness was coded by activity in medial orbitofrontal cortex, midinsular cortex, and in the anterior cingulate cortex (de Araujo et al. 2003c; Figs. 3 and 4).

Related evidence of neural correlates of subjective hedonic experience for taste and flavor was found in experiments investigating food synergism, which is the phenomenon whereby a combination of food elements elicits experiences that are more than the sum of food elements on their own. Thus, the combination of pure strawberry odor and pure sugar taste is more pleasant to many people than either the odor or the taste on their own. Neuroimaging evidence suggests the subjective enhance- ment correlates with activity in a lateral region of the midanterior orbitofrontal cortex (de Araujo et al. 2003c). A similar type of response was also found in the mid-anterior part of the orbitofrontal cortex for the strong subjective enhancement of umami taste that occurs after adding a tiny ribonucleotide to umami (de Araujo et al. 2003a).

Another approach has been to demonstrate the coding of the reward value of a stimulus by using a manipulation called selective or sensory-specific satiety, which is a form of reinforcer devaluation (Cabanac 1971; Le Magnen 1967; Rolls et al. 1981). This approach has been used in neuroimaging experiments by comparing human subjects who were presented with two food-related stimuli while hungry and again after eating to satiety on one food, which especially decreases its reward value (Figs. 3 and 4). The neuroimaging experiments using olfactory and whole-food stimuli showed that the activity in the mid-anterior parts of the orbitofrontal cortex tracks the changes in reward value of the two stimuli, such that the activity selectively decreases for the food eaten but not for the other food (Kringelbach et al. 2003; O'Doherty et al. 2000). Activity in the mid-anterior region of the orbitofrontal cortex not only showed a sensory-specific decrease in the reward value of the whole food eaten to satiety (while remaining high to the other food) but also correlated strongly to pleasantness ratings of the foods (Kringelbach et al. 2003).

A malfunction of these satiation mechanisms in the orbitofrontal cortex could explain the profound changes in eating habits (escalating desire for sweet food coupled with reduced satiety) that are often followed by enormous weight gain in patients with frontotemporal dementia. This progressive neurodegenerative disorder is associated with major and pervasive behavioral changes in personality and social conduct resembling those produced by orbitofrontal lesions (although it should be noted that more focal lesions to the orbitofrontal cortex have not to date been associated with obesity; Rahman et al. 1999).

In terms of direct causation of human pleasure, the subcortical structures demonstrated in animals interact with cortical structures such as the orbitofrontal cortex, the insula, and anterior cingulate cortex (Schoenbaum et al. 2006; Wallis 2007). But so far, not many other sites can be listed yet for which necessary or sufficient criteria are met by strong evidence that cortex causes pleasure. Cortical causation will need a closer look, as discussed below. Using MEG, it has been demonstrated that the pleasurable pain relief obtained from direct stimulation of the brainstem PVG/PAG in humans, perhaps involving endogenous opioid release, will elicit activity in the mid-anterior orbitofrontal cortex (Kringelbach et al. 2007a). As we mentioned earlier, human neuroimaging experiments have shown that this part of the orbitofrontal cortex is a prime candidate for the coding of subjective hedonic experiences 
of pleasure (Kringelbach 2005), and so we give it special attention below.

\section{Orbitofrontal cortex: apex of pleasure representation?}

A recent convergence of findings from neuroimaging, neuropsychology, and neurophysiology indicates that the human orbitofrontal cortex is best thought of as an important nexus for sensory integration, emotional processing, and hedonic experience (Figs. 5 and 6). It has become clear recently that the orbitofrontal cortex also has an important role in emotional disorders such as depression and addiction, and it is now possible to offer a tentative model of the functional neuroanatomy of the human orbitofrontal cortex in pleasure (Kringelbach 2005). a

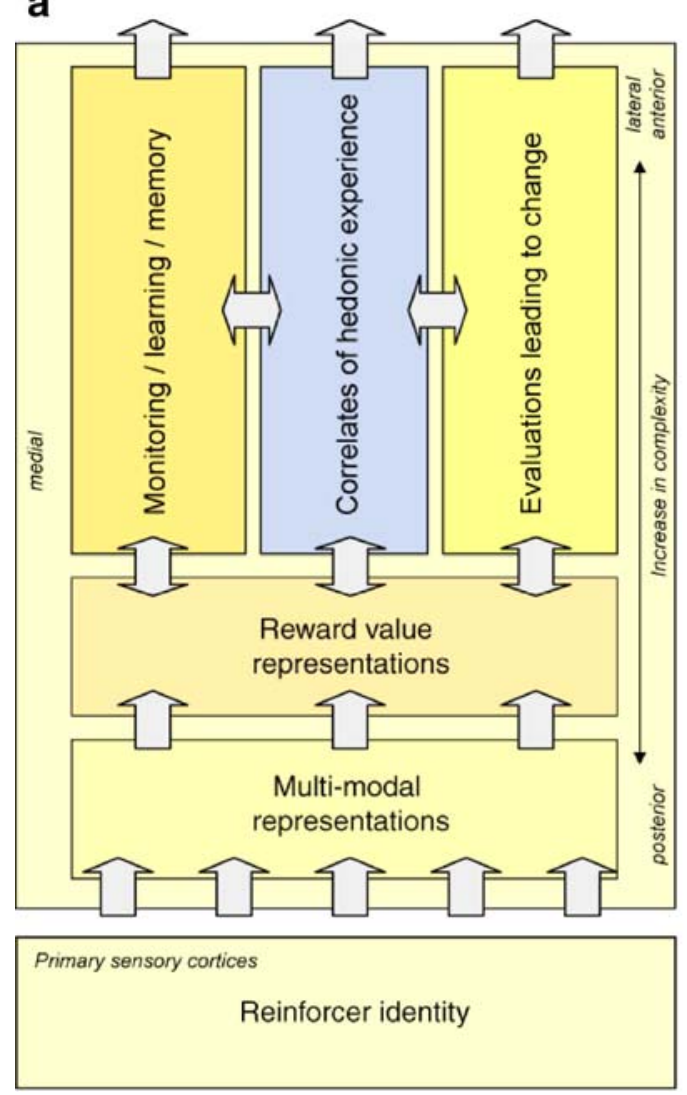

b

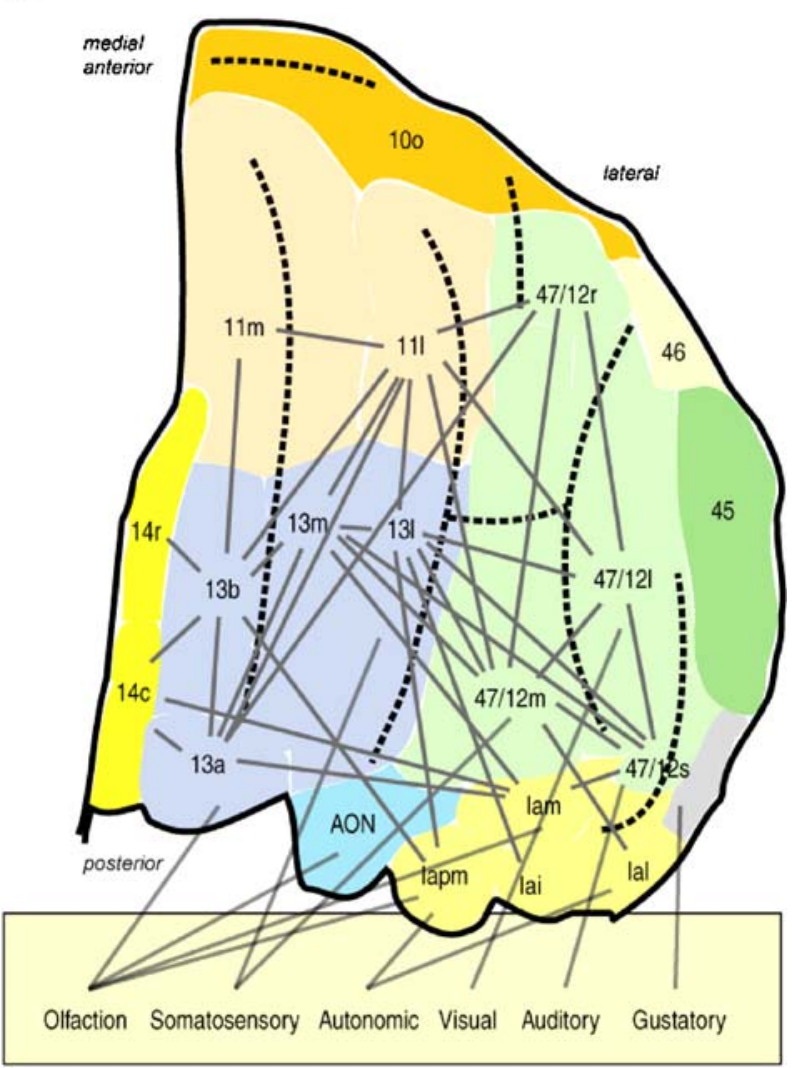

subsequent behavior (in lateral parts of the anterior orbitofrontal cortex with connections to anterior cingulate cortex), stored for valence learning/memory (in medial parts of the anterior orbitofrontal cortex), and made available for subjective hedonic experience (in midanterior orbitofrontal cortex). The reward value and the subjective hedonic experience can be modulated by hunger and other internal states. b In addition, there is important reciprocal information flowing between the various regions of the orbitofrontal cortex and other brain regions as demonstrated by the detailed inputs between the different sub-regions 
Fig. 6 Orbitofrontal cortex $(O F C)$ comparison in rats and primates. Homology between the prefrontal cortex in rat (orbital and agranular insular areas) and primates (OFC) is indicated by their similar patterns of connectivity with the mediodorsal thalamus (MD, green), amygdala (orange), and striatum/accumbens/pallidum system (pink). In both species, the $\mathrm{OFC}$ receives robust sensation input from sensory cortices and associative information from the amygdala, and in both sends motor and limbic outputs to the striatum and nucleus accumbens. A coronal example is shown in each box. AId Dorsal agranular insula, $A I v$ ventral agranular insula, $c$ central, $C D$ caudate, $L O$ lateral orbital, $m$ medial, $N A c$ nucleus accumbens core, $r A B L$ rostral basolateral amygdala, $V O$ ventral orbital, including ventrolateral and ventromedial orbital regions, $V P$ ventral pallidum. Reprinted with permission from Schoenbaum et al. (2006)

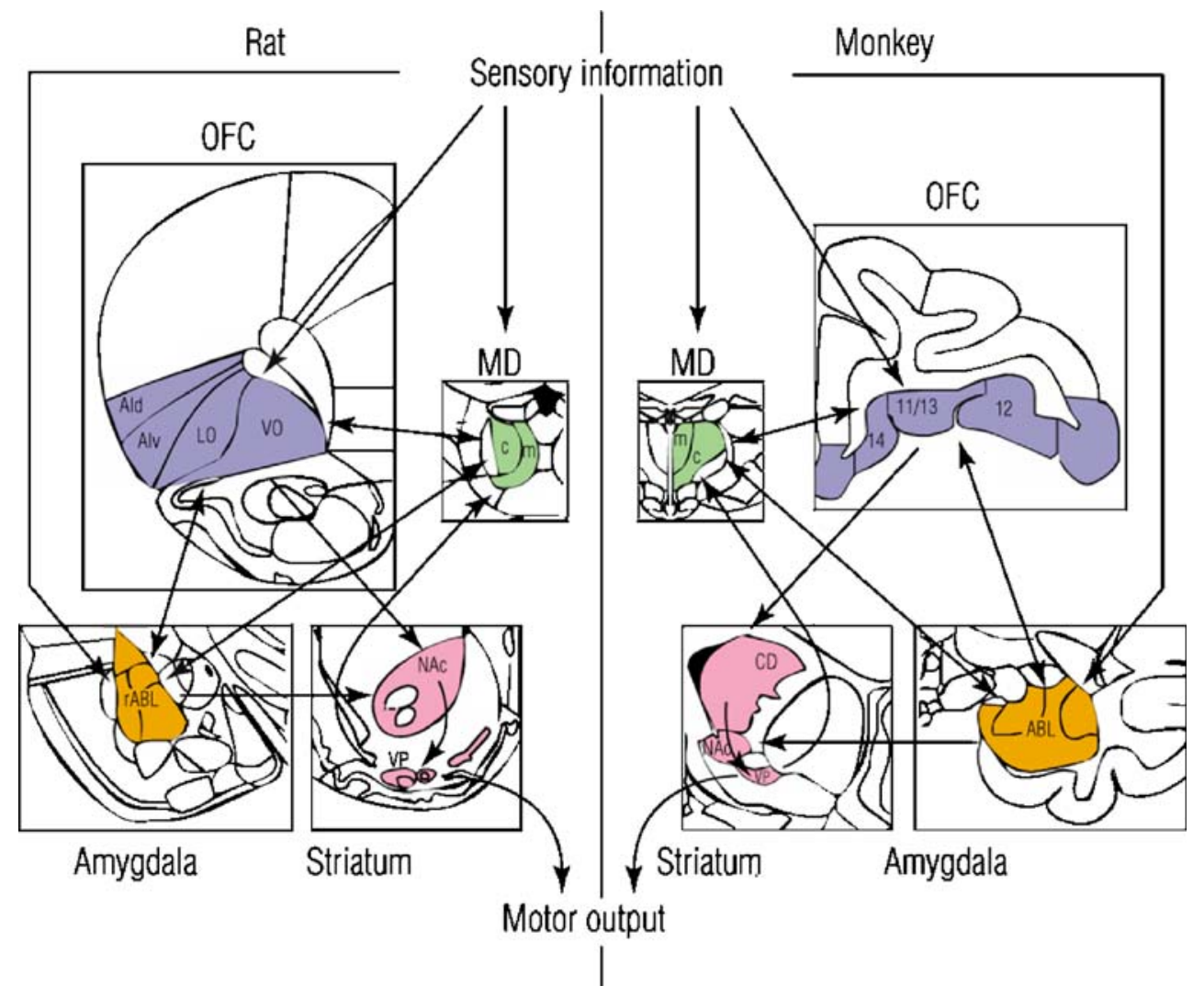

can be modulated by hunger and other internal states. At all times, important reciprocal information flows between the various regions of the orbitofrontal cortex and other brain regions including the insular cortex, anterior cingulate cortex, nucleus accumbens, ventral pallidum, and the amygdala (Figs. 5 and 6). Significant differences in terms of laterality have not been demonstrated in the orbitofrontal cortex. However, this is a highly heterogeneous brain region, and future neuroimaging and neuropsychology studies are likely to find many more functional distinctions between its constituent parts.

This model does not posit that medial orbitofrontal cortex only codes for the positive valence of rewards and vice versa for the lateral parts as coders of displeasure. Instead, the evidence from neuroimaging would seem to suggest that the valence of pleasures can be represented differently in different sub-parts of the orbitofrontal cortex. The activity (as indexed by the BOLD signal) in the medial orbitofrontal cortex would appear to correlate with the valence of rewards, such that pleasant stimuli elicit a higher BOLD signal than unpleasant stimuli, which is consistent with a monitoring role for the medial orbitofrontal cortex. The inverse appears to be true for the lateral parts of the orbitofrontal cortex, but with the important caveat that the lateral parts are mostly concerned with those unpleasant stimuli that can bring about a change in behavior-as negative reinforcers or cognitively avoided disincentives. Finally, the mid-anterior region of the orbitofrontal cortex would appear to integrate the valence with state-dependent mechanisms such as selective satiation and is thus a candidate region for taking part in the mediation of subjective hedonic experience. It would be of considerable interest to investigate whether any of these sub-regions of the orbitofrontal cortex are necessary or sufficient causes of pleasure or alternatively whether their role is restricted to cognitive elaboration of value and translation of hedonic affect into goal-directed plans.

\section{Cortical causation of human pleasure?}

The proposed link to subjective hedonic processing might make the orbitofrontal cortex an important gateway for neuroscientific analyses of human subjective conscious experience. Some have even suggested that the orbitofrontal and anterior cingulate cortices could be viewed as part of a global workspace for access to consciousness with the specific role of evaluating the affective valence of stimuli (Dehaene et al. 1998; Kringelbach 2008). In this context, it is interesting that the medial parts of the orbitofrontal are part of a proposed network for the baseline activity of the human brain at rest (Gusnard et al. 2001), as this would place the orbitofrontal cortex as a key node in the network 
subserving consciousness. This could potentially explain why all our subjective experiences have an emotional tone.

However, while the neuroimaging evidence clearly suggests that the orbitofrontal cortex is coding for pleasure, in so far that the activity correlates to the output of pleasure, it is presently not clear whether this activity also provides causal input to subjective pleasure experiences. We suggest that this possible causation link deserves further scrutiny, as it is currently not known whether orbitofrontal cortex (or related prefrontal sites) causes the consciousness of pleasure, whether it causes more basic hedonic 'liking' reactions to pleasure, whether it is primarily an effective point of integration between non-conscious and conscious hedonic processing into decision making, or perhaps none of these. One way of investigating this causation question would be to ask whether the orbitofrontal cortex is actually required for normal pleasure reactions or conscious feelings. Only scattered data are available, primarily from historical and case study sources. Prefrontal lobotomies were performed on thousands of human patients in the 1950s and may provide some insights (Valenstein 1986). If orbitofrontal or other prefrontal areas are necessary for basic 'liking' reactions, these lobotomy patients should no longer have been able to feel pleasure. Yet perhaps surprisingly from this perspective, prefrontal lobotomy may not produce a catastrophic loss of pleasure feelings as far as one can tell from the available literature. Although many subtle emotional deficits occur in how patients describe or act upon their emotions after damage to prefrontal cortex, the capacity for basic 'liking' reactions appeared to remain intact. Lobotomy patients were by no means oblivious to the pleasures of food, sex, or other rewards. And while modern analyses of more focal prefrontal lesions report deficits in cognitive-emotional processing of decisions of human patients, they generally do not indicate a total loss of the capacity for pleasures (Bechara et al. 2000; Damasio 1999; Damasio 2004; Hornak et al. 2003). Although apathy and lack of affect is sometimes reported after to the dorsomedial prefrontal cortex, the nearly opposite symptoms of euphoria, impulsiveness, and general emotional disinhibition may be reported after damage to the ventromedial prefrontal and orbitofrontal cortex (Tucker et al. 1995). Similarly, monkeys or rats with damage to orbitofrontal cortex (OFC) still respond robustly for rewards but are disrupted in subtle ways on the cognitive use of reward information to guide behavioral decisions (Burke et al. 2008; Izquierdo et al. 2004; Pears et al. 2003; Pickens et al. 2003; Rudebeck et al. 2006; Schoenbaum et al. 2006; Wallis 2007). As Schoenbaum and Shaham concluded, "the OFC does not appear to play an important role in the acute rewarding effect of cocaine or in relapse induced by acute exposure to the drug. This result is consistent with data showing that the
OFC is rarely necessary for animals to learn to respond for reward, presumably because of the operation of multiple, parallel learning systems" (Schoenbaum and Shaham 2007). Such considerations suggest that orbitofrontal cortex might be more important to translating hedonic information into cognitive representations and decisions than to generating a core 'liking' reaction to pleasant events (Dickinson and Balleine 2008).

Similar reservations might also apply to certain types of clinical 'anhedonia', which are reported to involve disruption of cortical activation patterns in orbitofrontal, insular, and other limbic regions (Keedwell et al. 2005; Mitterschiffthaler et al. 2003). On its face, anhedonia associated with depression, schizophrenia, and other pathological conditions implies a total lack of pleasure, including sensory pleasures. Yet, it is not entirely clear whether anhedonic patients truly lack the capacity for sensory pleasures or instead just undervalue rewards in more cognitive ways while preserving a capacity for basic pleasure. For example, most anhedonic patients with schizophrenia or depression still give essentially normal hedonic ratings to the taste of sucrose (even if they have slight intensity impairments; Berlin et al. 1998). That raises the possibility that clinical anhedonia may impair cognitive evaluations of life satisfaction yet leave intact more basic capacity for pleasure reactions. It would be valuable to gain more information on the pleasure capacities of patients diagnosed with clinical anhedonia.

Alternatives to idea that cortex causes pleasure are counterintuitive to many investigators, but may nonetheless still deserve further attention. These include the possibility that, even in humans, subcortical structures are the chief generators of basic pleasures (Izard 2007; Kringelbach 2008; Panksepp 2007; Smith et al. 2008; Steiner 1973). At its extreme, this position views hedonic reactions as arising from subcortical structures even when they are on their own and unable to interact with neocortex and is in part based on evidence that human reactions to pleasant events may persist after major cortical atrophy. For example, Shewmon et al. described several hydrocephalic cases, including a 6year-old boy with congenital "absence of cerebral tissue rostral to the thalamus, except for small mesial temporallobe remnants" and a tissue-lined cyst (p. 364), who nevertheless "smiled when spoken to and giggled when played with. These human interactions were much more intense than, and qualitatively different from, his positive reactions to favorite toys and music." (p. 366, Shewmon et al. 1999). Similarly, Merker suggested that hydrocephalic children "express pleasure by smiling and laughter, and aversion by "fussing," arching of the back, and crying (in many gradations), their faces being animated by these emotional states. A familiar adult can employ this responsiveness to build up play sequences predictably progressing 
from smiling, through giggling, to laughter, and great excitement on the part of the child." (p. 79, Merker 2007). Such cases of emotional reaction without (much) cortex raise fascinating questions for future consideration about the relative roles of cortical regions versus subcortical structures in human pleasures. However, no matter what conclusion is reached regarding pleasure generation, there seems general consensus that neocortex is crucial to link affect with complex cognition.

\section{Controversial subcortical pleasure generators? Dopamine and electrical brain stimulation}

Among subcortical generators of reactions to pleasure, it is important to discriminate those that truly generate hedonic 'liking' from those that only generate other non-hedonic components of reward. Several limbic substrates once thought to cause pleasure may have turned out not to do so after all. These include the mesolimbic dopamine system, as well as the wider ventral brain substrate that supports self-stimulation electrodes (e.g., medial forebrain bundle and related structures).

\section{Beyond pleasure for dopamine?}

Mesolimbic dopamine was long regarded as a pleasure neurotransmitter but now seems increasingly thought by many neuroscientists to fail to live up to its pleasure label. One line of evidence against a pleasure-causing role is that mesolimbic dopamine neurons may not reliably be activated by pleasure per se but instead by predictive, motivational, or attentional properties rather than hedonic properties of reward stimuli (Carelli 2004; Cheer et al. 2007; Redgrave and Gurney 2006; Salamone et al. 2007; Schultz et al. 1997). Another line of evidence is that, when 'liking' versus 'wanting' are teased apart by brain manipulations, specific manipulation of dopamine signaling either up or down simply fail to shift 'liking' reactions to pleasure reliably in either animals or humans (Berridge 2007; Brauer and De Wit 1997; Cannon and Palmiter 2003; Evans et al. 2006; Leyton 2008; Leyton et al. 2002; Leyton et al. 2005; Peciña et al. 2003; Robinson et al. 2005; Tindell et al. 2005; Volkow et al. 2002; Volkow et al. 2006). A third line of evidence is that dopamine systems may also be activated by aversive or frankly non-rewarding stimuli, at least tonic dopamine release pulses that last on the order of a few minutes (Ferrari et al. 2003; Horvitz 2000; Salamone 1994; Scott et al. 2006). Overall, the mesolimbic dopamine system often seems surprisingly unable to alter basic hedonic reactions to pleasure directly, in contrast to opioid and other true brain hedonic hotspots that generate 'liking' (Berridge 2007).
Dopamine roles in reward learning, prediction, and motivation

A popular alternative interpretation of mesolimbic dopamine's role in reward has been that it mediates learning and predictions about future reward events. This alternative draws on the distinction between phasic dopamine signals (spike-triggered release limited to within synapses) and tonic dopamine signals (spike-independent release extending outside synapses) and typically assigns a learning role specifically to phasic signals (Grace 1991; Grace et al. 2007; Niv et al. 2007; Phillips et al. 2003; Schultz 1997; 2007). Learning and prediction roles of dopamine have been conceptualized as teaching signals, S-S prediction signals about future rewards, and S-R stamping-in or habit reinforcement (Day and Carelli 2007; Di Chiara and Bassareo 2007; Everitt and Robbins 2005; Fields et al. 2007; Hyman et al. 2006; Kelley 2004; Pessiglione et al. 2006; Schultz 2006; Schultz et al. 1997; Tobler et al. 2005; Wise 2006). Many fascinating studies have revealed predictive reward signals to be often coded by dopamine systems (Bayer and Glimcher 2005; Di Chiara and Bassareo 2007; Fields et al. 2007; Knutson et al. 2001; Knutson et al. 2007; McClure et al. 2003; Nicola et al. 2005; O’Doherty et al. 2006; Pessiglione et al. 2006; Phillips et al. 2003; Roitman et al. 2004; Schultz 2006; Schultz et al. 1997; Tobler et al. 2005) and by target systems in nucleus accumbens and related forebrain structures (Aldridge et al. 1993; Barnes et al. 2005; Carelli 2004; Cromwell et al. 2005; Day and Carelli 2007; Ghitza et al. 2004; Roitman et al. 2005; Taha and Fields 2006; Tindell et al. 2004; Wan and Peoples 2006).

Cellular and molecular studies of long-term potentiation (LTP) and long-term depression (LTD) of neurotransmission onto neuronal targets of dopamine add ostensible mechanisms for prediction and learning about rewards that give pleasure (Berke 2003; Fields et al. 2007; Hyman et al. 2006; Kelley 2004; Malenka and Bear 2004). Similarly, studies of learning consolidation, and of striatum-accumbens interactions with associative brain structures such as amygdala, hippocampus, prefrontal cortex, and anterior cingulate cortex, have been conducted in support of this hypothesis (Balleine 2005; Balleine and Killcross 2006; Cardinal and Everitt 2004; Cohen et al. 2005; Everitt and Robbins 2005; Feldman Barrett and Wager 2006; Schultz 2006).

Dopamine-beyond learning too?

Yet it has recently been questioned whether dopamine is truly needed to learn about pleasures or truly ever causes new learning directly, at least as a teaching signal, prediction error, or stamping-in mechanism for stimulus- 
stimulus or stimulus-response associations (Berridge 2007; Hnasko et al. 2005; Redgrave and Gurney 2006; Robinson et al. 2005).

One question concerns the distinction between phasic versus tonic dopamine signals, which is crucial to most contemporary learning models for dopamine (Schultz 2007). Some have asked whether it is entirely clear that neurons that receive dopamine signals can always reliably track the difference between phasic and tonic inputs (Shizgal and Arvanitogiannis 2003; Wightman and Robinson 2002). Further, much data suggests that tonic levels of dopamine affect learning in ways that are not captured by current phasic signal models. For example, what happens to learning and prediction when tonic dopamine is elevated? If tonic and phasic signals are separately segregated, some might expect no effect of tonic dopamine on learning. Others have suggested that the onset of tonic elevations in extracellular dopamine signals, such as produced by administration of amphetamine or related addictive drug, might sometimes function much like a phasic signal to cause a prediction error or teaching signal, and so strengthen over-learning in addiction. Still, others have suggested that tonic dopamine elevation by amphetamine or similar drugs might shut down firing and phasic dopamine release to suppress learning and cue-triggered predictions mediated by phasic signals due to autoreceptor activation and related down-regulatory mechanisms that feed back during tonic receptor stimulation to inhibit phasic activity in dopamine neurons. Additionally, even if phasic dopamine release survived tonic elevation, the receptors on post-synaptic neurons face a degraded signal-to-noise ratio when swamped by amphetamine-induced tonic elevations in dopamine and might be hard pressed to detect any further phasic elevations in dopamine. Such lines of thought imply that there might be little learning about natural pleasures or little learned performance left in a brain on amphetamine if phasic dopamine signals were a chief mechanism for learning and reward prediction.

Yet despite all that, considerable neural and behavioral evidence suggests that amphetamine-induced tonic elevations of dopamine actually can often enhance both learning and cue-triggered learned performance. This might be explained if tonic dopamine facilitates phasic nondopamine signal processing that mediates learning in downstream limbic structures. For example, a dose of amphetamine that elevates tonic dopamine actually amplifies the neural encoding of phasic 100-ms learned reward cue-triggered signals in the ventral pallidum (which probably reach ventral pallidum via nondopamine afferent projections) that convey learned information about future reward (Tindell et al. 2006). Similarly, tonic dopamine elevation by amphetamine elevates behavioral performance triggered by reward cues or directed toward obtaining them (in ways that are too specific to the learned motivating value of cues to be explained by tonic activation or general response strengthening effects of a drug; Cardinal et al. 2002; Everitt et al. 2001; Everitt et al. 1999; Wyvell and Berridge 2001). In short, tonic dopamine affects reward learning and learned performance, involving complexities that might not be expected from a pure focus on phasic dopamine signals.

More fundamentally, while a number of neuroscientists have shown that the firing of dopamine neurons correlates beautifully to patterns expected from computational models of reward learning, questions have recently emerged about whether the dopamine signals are actually ever needed to cause the learning to occur (Berridge 2007; Cagniard et al. 2006a; Palmiter 2007; Panksepp 2005; Redgrave and Gurney 2006). Regarding whether dopamine is needed at all to learn about rewards, several forms of reward learning have recently been shown to proceed normally in the brains of mice that completely lack dopamine signals (due to genetic manipulation that prevents dopamine synthesis by neurons), presumably both phasic and tonic signals (Hnasko et al. 2005; Robinson et al. 2005). Conversely, elevation of dopamine neurotransmission by a different genetic manipulation may fail to cause or alter teaching signals needed for new reward learning (Cagniard et al. 2006a; Cagniard et al. 2006b; Niv et al. 2007; Tindell et al. 2005; Yin et al. 2006). Such observations raise room to doubts whether correlations between dopamine signals and learning necessarily imply that the dopamine has a strong causal role in learning.

Such considerations have led to suggestions that the primary role of mesolimbic dopamine in reward is to facilitate some other process besides either learning or pleasure 'liking'. Suggestions have included motivational incentive salience, arousal, motivation, and memory consolidation (Barbano and Cador 2007; Berridge 2007; Niv et al. 2007; Redgrave and Gurney 2006; Robbins and Everitt 2007; Salamone et al. 2007). If so, long-term plasticity in limbic structures, such as synaptic LTP and LTD, might reflect enduring motivation changes amongst other things rather than represent new learned associations via Hebbian synaptic coupling or prediction computation. Thus, the debate continues over the role of dopamine in reward.

\section{Beyond pleasure electrodes?}

A related case of a brain hedonic substrate that may fail after all to live up to its name may be so-called brain pleasure electrodes in limbic sites (Hernandez et al. 2006; Kringelbach et al. 2007a; Olds and Milner 1954; Fig. 7). Originally discovered in rats and conceived as activating pleasure centers in the brain (Olds 1956), recent reappraisal have been prompted by observations that such electrodes may cause increased 'wanting' without 'liking' for rewards, 
Fig. 7 Pleasure electrodes or not? Comparison of famous examples of controversial 'pleasure electrodes' in rat (from Olds 1961 ) and in human (patient B-19, a young man, from Heath 1972). Thick black lines show the electrodes (insulated except at tip; red dots indicate their stimulating tips). Both the rat and the human pressed for electrode stimulation up to thousands of times, but recently questions have been raised whether both electrodes might have produced merely a pure form of 'wanting' (incentive salience) rather than actual 'liking' (true hedonic pleasure). Reprinted from Smith et al. (2008)

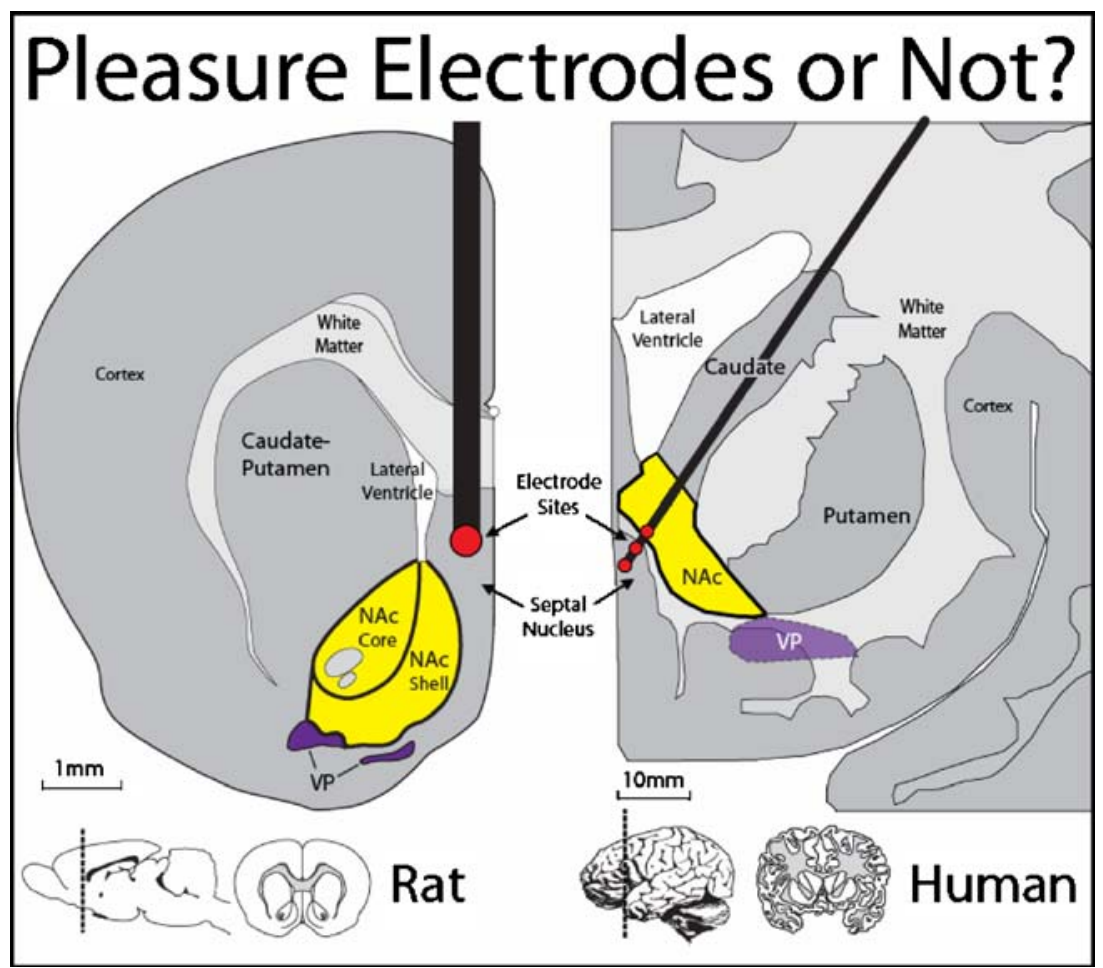

similar to dopamine (Berridge 2003b; Green et al. 2008; Kringelbach 2008; Kringelbach et al. 2007b; Smith et al. 2008). Brain stimulation electrodes are vigorously selfstimulated by rats in structures such as lateral hypothalamus, septum, accumbens, or the medial forebrain bundle (Olds and Milner 1954; Shizgal et al. 2001) and often simultaneously motivate animals to eat, drink, engage in sex, etc. (Hoebel 1988; Valenstein et al. 1970). However, the same electrodes that make rats 'want' to eat food more voraciously still fail to make rats 'like' food more hedonically (Berridge and Valenstein 1991).

In humans, famous cases of intense 'pleasure electrodes' are cited by many textbooks (Heath 1972). But when those cases are scrutinized more closely, a surprising conclusion may emerge that most did not cause much sensory pleasure after all, not even the most famous (Berridge 2003b; Smith et al. 2008). For example, a much-cited case is "B-19", a young man implanted with stimulation electrodes in septum/accumbens region by Heath and colleagues in the 1960s (Heath 1972). B-19 voraciously self-stimulated his electrode and protested when the stimulation button was taken away (Fig. 7). In addition, his electrode caused "feelings of pleasure, alertness, and warmth (goodwill); he had feelings of sexual arousal and described a compulsion to masturbate" (p. 6, Heath 1972).

But did the electrode really cause a pleasure sensation? Perhaps not. B-19 never was quoted as saying it did; not even an exclamation or anything like "Oh-that feels nice!". Instead B19's electrode-stimulation-evoked desire to stimulate again and strong sexual arousal-while never producing sexual orgasm or clear evidence of actual pleasure sensation. And the stimulation never served as a substitute for sexual acts. What it did instead was to make him want to do more sexual acts, just as it made him want to press the button more.

Similarly, a female patient implanted with an electrode decades later compulsively stimulated her electrode at home (Portenoy et al. 1986). "At its most frequent, the patient self-stimulated throughout the day, neglecting personal hygiene and family commitments" (p. 279, Portenoy et al. 1986). When her electrode was stimulated in the clinic, it produced a strong desire to drink liquids and some erotic feelings, as well as a continuing desire to stimulate again. However, "Though sexual arousal was prominent, no orgasm occurred" (p. 279, Portenoy et al. 1986). This seems a bit similar to B-19. "She described erotic sensations often intermixed with an undercurrent of anxiety. She also noted extreme thirst, drinking copiously during the session, and alternating generalized hot and cold sensations" (p. 282, Portenoy et al. 1986). Clearly, this woman felt a mixture of subjective feelings, but the description's emphasis is on aversive thirst and anxietywithout evidence of distinct pleasure sensations. Of course, to suggest that such pleasure electrodes failed to cause real pleasure does not mean that no electrode ever did so, much less that future pleasure electrodes never will. But it does 
mean that, if even the most prototypical and classic cases of 'pleasure electrodes' from the past are open to doubt, closer scrutiny of deep brain stimulation (DBS) electrodes may be needed in the future: Do they really cause pleasure? (Green et al. 2008; Kringelbach et al. 2007b).

Incentive salience as potential explanation for dopamine and electrodes

What could such reward electrodes be doing, if not pleasure? One possible explanation is that electrode activation might enhance motivational value in the form of incentive salience attribution to surroundings and stimuli perceived at that moment, especially to the act of stimulating the electrode and the stimuli that surround it. If the electrodes caused 'wanting', a person might well describe a sudden feeling that life was suddenly more attractive, desirable, and compelling to pursue. If it caused 'wanting' attribution to the button and the act of pressing it, people might well 'want' to activate their electrode again, even if it produced no pleasure sensation. That would be mere incentive salience 'wanting' — without hedonic 'liking'. It would be possible in that case to 'want' to press the electrode again, without ever gaining significant pleasure or even necessarily having a clear expectation of gaining pleasure. Similar 'wanting' interpretations have been applied more generally to the role of mesolimbic dopamine in reward (Berridge 2007; Berridge and Robinson 1998).

The psychology of incentive salience creates such possibilities for irrational desire, which extend beyond pleasure electrodes to addictive drugs and perhaps to some targets of other compulsive motivations, and which commonly involve activation of mesolimbic dopamine systems (Berridge and Aldridge 2008; Robinson and Berridge 1993; Robinson and Berridge 2003). Defined as a want for something you neither like nor expect to like, strongly irrational desire may be rare but does exist (the electrode cases above might be examples). In animal experiments, irrational 'wanting' has been suggested to be created through activation of brain dopamine-related systems via systemic or intra-accumbens amphetamine administration and by psychostimulant-induced neural sensitization of accumbens-related systems (Flagel et al. 2007; Peciña et al. 2003; Tindell et al. 2005; Uslaner et al. 2006; Vezina 2004; Wyvell and Berridge 2001). In humans, drug-induced irrational 'wanting' has been suggested to occur via incentive sensitization in some drug addicts, which may create a motivational compulsion to take drugs again even if a drug is not particularly pleasant and even after recovery from withdrawal (Robinson and Berridge 1993; Robinson and Berridge 2003). Considerable evidence has recently emerged to bear on such excesses of desire (Boileau et al. 2006; Boileau et al. 2007; Camerer 2006; de Wit et al.
2002; Evans et al. 2006; Everitt and Robbins 2005; Finlayson et al. 2007; Lawrence et al. 2003; Leyton et al. 2002; Leyton et al. 2005; Robinson and Berridge 2003; Vanderschuren and Everitt 2005; Wiers et al. 2007; Wiers and Stacy 2006).

\section{In what ways are the brain mechanisms of pleasure linked to human happiness?}

A final question regarding the comparison of humans to animals is to ask how relevant pleasure is to human happiness. That is, in what role do brain mechanisms of sensory pleasures, which might be shared by animals and humans alike, play in the more exalted phenomenon of happiness, which might be relatively unique to humans and perhaps even only a fortunate few?

Sigmund Freud, for instance, took a strongly hedonic view about how happiness relates to pleasure (Freud and Riviere 1930). In response to his own question about what people demand of life and wish to achieve in it, Freud replied "The answer to this can hardly be in doubt. They strive after happiness; they want to become happy and to remain so. This endeavor has two sides, a positive and a negative aim. It aims, on the one hand, at an absence of pain and displeasure, and, on the other, at the experiencing of strong feelings of pleasure" (Freud and Riviere 1930; p.76). Freud's answer equates pleasure with happiness. According to this view, the more pleasure you have (while avoiding displeasure), the happier you are. To the degree that such a hedonic answer is correct, brain mechanisms of pleasure might be virtually identical to brain mechanisms of happiness.

But on the other hand, others have contended instead that human happiness involves much more than mere pleasure and requires additional achievements in the cognitive, aesthetic, moral, or other domains (Cabanac 2008; Higgins 2006; Kahneman et al. 1999; Kringelbach 2008; Leknes and Tracey 2008; Mill et al. 1998). For instance, John Stuart Mill wrote: "It is better to be a human being dissatisfied than a pig satisfied; better to be Socrates dissatisfied than a fool satisfied." (Mill et al. 1998, p. 57). By Mill's view, pleasure in a pig or fool is not enough for happiness because true happiness hinges on a superior kind of psychological richness that is unique to more enlightened humans. Mill asserted further that even if anyone could "know both sides" and compare the experience of humans and of animals, "Few human creatures would consent to be changed into any of the lower animals, for a promise of the fullest allowance of a beast's pleasures" (p.57). While it is difficult to speculate whether many beasts would consent to the reverse if they could know both sides, still many people would agree with Mill that human well-being often turns on 
considerations about family, culture, morality, success, justice, or other higher values.

Perhaps happiness cannot be reduced to pleasure alone, and pleasure is but a fleeting moment in the state which is happiness. But the attainment of happiness must surely include the ready capacity for pleasure reactions. Some might even suggest that 'true' happiness or bliss might be a state of 'liking' without 'wanting' - which with the current available neuroscientific evidence is actually becoming a testable hypothesis.

\section{A glossary of reward definitions}

Discussions about pleasure can be frustrating when different participants mean different things when using the same term. To avoid misunderstandings, we have included brief definitions of what we mean by particular terms. Our goal is not to impose our definitions on readers who prefer different ones but simply to help readers keep track of what terms mean here.

Affective valence or hedonic impact Affective valence is the hedonic niceness or nastiness ('liking' versus 'disliking') of reward or aversion that is essential to emotions. We stress here that the hedonic valence of pleasure is always a braingenerated process or reaction that must be actively added to the stimulus by specialized neural systems (such as accumbens/pallidal hedonic hotspots). Hedonic valence is neither an inherent property of a stimulus nor a mere epiphenomenon but results as an objective neural-psychological process from the interactive ability of the stimulus to engage hedonic brain systems. In our view, this objective side of pleasure mechanisms aids the development of an affective neuroscience of positive affect. The term hedonic is often restricted to positive pleasures in particular (and not displeasures), perhaps in part because the word is derived from the ancient Greek hedone, referring to the Cyreniac philosophical principle that pleasure is the proper goal of action, and hedys for sweet and pleasant.

Learning Associative Pavlovian or instrumental learning forms link between stimuli or behavioral events. Cognitive learning mechanisms additionally form higher-order rulebased predictions of future events, declarative expectations, and goal-directed plans based on experience.

Liking (without quotation marks) Subjective hedonic reactions. This is the everyday sense of the word liking or pleasure, referring most directly to a conscious experience or subjective feeling of niceness.

'Liking' (with quotation marks) An objective hedonic reaction, measured behaviorally or neurally, whether or not accompanied by conscious pleasure. Core 'liking' reactions result from activity in identifiable brain systems that paint hedonic value on a sensation such as sweetness. Behavioral 'liking' reactions have been especially useful for mapping causal hedonic hotspots in the brain, particularly in the form of 'liking'/ 'disliking' facial expressions to tastes that are homologous between humans and many other mammals. In humans, 'liking' reactions on their own have been shown in the form of unconscious pleasures, in cases where people remain unaware of an emotional stimulus and of their own hedonic reaction to it.

Pleasure Positive hedonic valence, as a 'liking' reaction or subjective liking reaction to the hedonic impact of a stimulus. In its most commonly used sense, pleasure refers typically to the subjective experience of conscious niceness. In a more most basic affective neuroscience sense suggested here, pleasure can also refer to a simpler core 'liking' reaction generated by hedonic brain systemswhether a subjective feeling of pleasure is consciously felt or not. Core 'liking' reactions, we suggest, are ordinarily translated into conscious pleasure feelings by additional cognitive brain mechanisms that underlie subjective awareness (just as unconscious visual processes may be translated into conscious visual sensations by awareness-generating mechanisms). That is, core 'liking' is a component of conscious liking in pleasure. But under some conditions in humans and animals, objective neural processing of pleasure may occur independently without conscious awareness as merely an unconscious 'liking' reaction.

Pleasure, neural causation of A brain mechanism such as a hedonic hotspot, in which neural activation causes an increase in objective 'liking' reactions, or in subjective ratings or experiences of conscious pleasure, or both. We distinguish here further between 'sufficient cause' and 'necessary cause' mechanisms. Necessary causation implies that if activity in a brain region is a necessary cause of pleasure, then the presence of this pleasure relies on activity in this brain region. The mere presence of this neural activity does not, however, imply that pleasure will occur.

In contrast, sufficient causation implies that if activity in a brain region is a sufficient cause of behavioral changes related to pleasure, then the presence of activity in this brain region produces behavioral changes. However, another cause may alternatively cause these behavioral changes, and thus, the presence of these changes does not imply the presence of activity in a brain region.

This means that a sufficient cause is a brain substrate able to generate increases in pleasure above normal or baseline levels (so that an activating manipulation results in magnification of hedonic impact). A necessary cause is a brain substrate needed for normal levels of pleasure 
(so that damage to it results in the loss of positive 'liking' reactions or an increase in dysphoric 'disliking' reactions or both). Clearly, some brain substrates may function as both necessary and sufficient causes for pleasure. However, other brain mechanism may function as sufficient causes only, contributing to pleasure enhancements but not needed for the hedonic impact of normal sensory pleasures.

Pleasure, neural coding of A brain mechanism in which activation correlates highly with the occurrence of pleasure, so that the neural activation is a reliable brain marker for pleasure. A neural code may function also as a neural cause for pleasure, and is often presumed to do so. However, a neural code sometimes arises as a consequence rather than a cause of pleasure (and instead may cause something else such as a related cognition). Coding activity in brain regions is, therefore, a larger category than pleasure causation, as coding includes activity arising from the subcategory of pleasure causes, as well as other brain regions not involved in this but rather in other functions that further process pleasure signals such as complex emotion, memory, cognition, etc. Coding activity is thus both related to the input registration of pleasure itself and also to the output activation of brain regions related to downstream consequences of pleasure. For these reasons, we consider coding and causation separately.

Positive reinforcement or reinforcer Positive reinforcement is sometimes used to denote pleasure, and positive reinforcer to denote a pleasure-causing stimulus, but we believe positive reinforcer is an ambiguous term because it has pleasure-free meanings, too. For example, pleasure was not stipulated in traditional concepts of positive reinforcement by Skinner (1938) or Hull (1951). Instead, behaviorist definitions of reinforcement simply meant strengthening of an observed behavioral response ( $\mathrm{S}-\mathrm{R}$ stamping-in), strengthening of a learned association between two stimuli ( $\mathrm{S}-\mathrm{S}$ associations), or an increase in the frequency of a learned operant emission (without positing any particular affective, learning, or neural mechanisms). We suggest that defining pleasure solely in terms of positive reinforcement amounts to outsourcing the difficult definition of pleasure to a behavioral measure of learning. A definition of pleasure as positive reinforcement also runs into empirical problems of double dissociations between pleasure and reinforcement. That is, pleasure may occur without behavioral positive reinforcement (in situations that do not involve learned responses). Conversely, positive reinforcement may occur without pleasure (e.g., by activating 'wanting' without 'liking' via false pleasure electrodes or via dopamine or by traditional S-R habit strengthening mechanisms). For these reasons, we believe it necessary to grapple directly with pleasure and reward rather than rely on positive reinforcement terms.

Reward A composite psychological process requiring multiple brain systems. A single instance of reward typically contains all three 'liking', 'wanting', and learning components. Brain manipulations may sometimes dissociate the components and change one much more than others. In most basic form, each component can occur without conscious awareness (i.e., core 'liking', core 'wanting', implicit learning). To be elaborated into the conscious forms that we all experience, the components are posited to require further processing by additional cognitive-related brain mechanisms, which generate awareness.

Wanting (without quotation marks) The everyday sense of the word as a subjective desire. Conscious wanting typically is distinguished by requiring cortical mechanisms that generate declarative goals (based on memory or imagery): you want something in particular and may imagine it in advance of getting it.

Wanting' (with quotation marks) Incentive salience, a motivational process within reward that mirrors hedonic 'liking' and makes stimuli attractive when attributed to them by mesolimbic brain systems. Incentive salience is highly influenced by mesolimbic dopamine neurotransmission (though other neurotransmitters and structures also are involved). Importantly, incentive salience is not hedonic impact or pleasure. That is why one can 'want' a reward without necessarily 'liking' the same reward. Irrational 'wanting' without liking can occur via incentive sensitization in drug addiction, false pleasure electrodes, and similar cases because 'wanting' mechanisms are largely subcortical and separable from cortically mediated declarative expectation and conscious planning. Thus, for example, addicts may irrationally and compulsively 'want' to take drugs even if, at a more cognitive and conscious level, they do not want to do so.

Acknowledgments We thank Kyle Smith, Stephen Mahler, Eric Jackson, and our anonymous reviewers for helpful comments on an earlier version of the manuscript. Our research is supported by grants from the TrygFonden Charitable Foundation to MLK and from the NIH to KCB (MH63644 and DA015188).

\section{References}

Aldridge JW, Berridge KC, Herman M, Zimmer L (1993) Neuronal coding of serial order: syntax of grooming in the neostriatum. Psychol Sci 4:391-395

Aldridge JW, Berridge KC (2008) Neural coding of pleasure: "RoseTinted Glasses" of the Ventral Pallidum. In: Kringelbach ML, 
Berridge KC (eds) Pleasures of the Brain. Oxford University Press, Oxford (in press )

Anderson AK, Sobel N (2003) Dissociating intensity from valence as sensory inputs to emotion. Neuron 39:581-583

Baldo BA, Kelley AE (2007) Discrete neurochemical coding of distinguishable motivational processes: insights from nucleus accumbens control of feeding. Psychopharmacology (Berl) 191:439-459

Balleine BW (2005) Neural bases of food-seeking: affect, arousal and reward in corticostriatolimbic circuits. Physiol Behav 86:717730

Balleine B, Killcross S (1994) Effects of ibotenic acid lesions of the nucleus accumbens on instrumental action. Behav Brain Res 65:181-193

Balleine BW, Killcross S (2006) Parallel incentive processing: an integrated view of amygdala function. Trends Neurosci 29:272279

Barbano MF, Cador M (2007) Opioids for hedonic experience and dopamine to get ready for it. Psychopharmacology (Berl) 191:497-506

Barnes TD, Kubota Y, Hu D, Jin DZ, Graybiel AM (2005) Activity of striatal neurons reflects dynamic encoding and recoding of procedural memories. Nature 437:1158-61

Barrett LF, Lindquist KA, Bliss-Moreau E, Duncan S, Gendron M, Mize J, Brennan L (2007a) Of mice and men: natural kinds of emotions in the mammalian brain? A response to Panksepp and Izard. Perspectives on Psychological Science 2:297-312

Barrett LF, Mesquita B, Ochsner KN, Gross JJ (2007b) The experience of emotion. Annu Rev Psychol 58:373-403

Bayer HM, Glimcher PW (2005) Midbrain dopamine neurons encode a quantitative reward prediction error signal. Neuron 47:129-141

Beaver JD, Lawrence AD, van Ditzhuijzen J, Davis MH, Woods A, Calder AJ (2006) Individual differences in reward drive predict neural responses to images of food. J Neurosci 26:5160-5166

Bechara A, Damasio H, Tranel D, Damasio AR (1997) Deciding advantageously before knowing the advantageous strategy. Science 275:1293-1295

Bechara A, Damasio H, Damasio AR (2000) Emotion, decision making and the orbitofrontal cortex. Cereb Cortex 10:295-307

Berke JD (2003) Learning and memory mechanisms involved in compulsive drug use and relapse. In: Wang JQ (ed) Drugs of abuse: neurological reviews and protocols (methods in molecular medicine). Humana, Totowa, NJ, pp 75-101

Berlin I, Givry-Steiner L, Lecrubier Y, Puech AJ (1998) Measures of anhedonia and hedonic responses to sucrose in depressive and schizophrenic patients in comparison with healthy subjects. Eur Psychiatry 13:303-309

Berns GS, McClure SM, Pagnoni G, Montague PR (2001) Predictability modulates human brain response to reward. J Neurosci 21:2793-2798

Berridge KC (2000) Measuring hedonic impact in animals and infants: microstructure of affective taste reactivity patterns. Neurosci Biobehav Rev 24:173-198

Berridge KC (2003a) Comparing the emotional brain of humans to other animals. In: Davidson RJ, Goldsmith HH, Scherer K (eds) Handbook of affective sciences. Oxford University Press, Oxford

Berridge KC (2003b) Pleasures of the brain. Brain Cogn 52:106-128

Berridge KC (2007) The debate over dopamine's role in reward: the case for incentive salience. Psychopharmacology (Berl) 191:391431

Berridge KC, Valenstein ES (1991) What psychological process mediates feeding evoked by electrical stimulation of the lateral hypothalamus? Behav Neurosci 105:3-14

Berridge KC, Robinson TE (1998) What is the role of dopamine in reward: hedonic impact, reward learning, or incentive salience? Brain Res Rev 28:309-369
Berridge KC, Robinson TE (2003) Parsing reward. Trends Neurosci. 26:507-513

Berridge KC, Aldridge JW (2008) Decision utility, incentive salience, and cue-triggered 'wanting'. In: Bargh J, Morsella E (eds) The psychology of action. Oxford University Press, New York (in press)

Blood AJ, Zatorre RJ (2001) Intensely pleasurable responses to music correlate with activity in brain regions implicated in reward and emotion. Proc Natl Acad Sci U S A 98:11818-11823

Boileau I, Dagher A, Leyton M, Gunn RN, Baker GB, Diksic M, Benkelfat C (2006) Modeling sensitization to stimulants in humans: an [11C]raclopride/positron emission tomography study in healthy men. Arch Gen Psychiatry 63:1386-1395

Boileau I, Dagher A, Leyton M, Welfeld K, Booij L, Diksic M, Benkelfat C (2007) Conditioned dopamine release in humans: a positron emission tomography [11C]raclopride study with amphetamine. J Neurosci 27:3998-4003

Brauer LH, De Wit H (1997) High dose pimozide does not block amphetamine-induced euphoria in normal volunteers. Pharmacol Biochem Behav 56:265-72

Burke KA, Miller D, Schoenbaum G (2008) Conditioned Reinforcement and the specialized role of corticolimbic circuits in the pursuit of happiness and other more specific rewards. In: Kringelbach ML, Berridge KC (eds) Pleasures of the brain. Oxford University Press, Oxford, UK (in press)

Cabanac M (1971) Physiological role of pleasure. Science 173:11031107

Cabanac M (1992) Pleasure: the common currency. J Theor Biol 155:173-200

Cabanac M (2008) The dialectics of pleasure. In: Kringelbach ML, Berridge KC (eds) Pleasures of the brain. Oxford University Press, Oxford, UK (in press)

Cagniard B, Balsam PD, Brunner D, Zhuang X (2006a) Mice with chronically elevated dopamine exhibit enhanced motivation, but not learning, for a food reward. Neuropsychopharmacology 31:1362-1670

Cagniard B, Beeler JA, Britt JP, McGehee DS, Marinelli M, Zhuang X (2006b) Dopamine scales performance in the absence of new learning. Neuron 51:541-547

Camerer CF (2006) Wanting, liking, and learning: neuroscience and paternalism. The University of Chicago Law Review 73:87-110

Cannon CM, Palmiter RD (2003) Reward without dopamine. J Neurosci 23:10827-10831

Cardinal RN, Everitt BJ (2004) Neural and psychological mechanisms underlying appetitive learning: links to drug addiction. Curr Opin Neurobiol 14:156-162

Cardinal RN, Parkinson JA, Hall J, Everitt BJ (2002) Emotion and motivation: the role of the amygdala, ventral striatum, and prefrontal cortex. Neurosci Biobehav Rev 26:321-352

Carelli RM (2004) Nucleus accumbens cell firing and rapid dopamine signaling during goal-directed behaviors in rats. Neuropharmacology 47(Suppl 1):180-189

Cheer JF, Aragona BJ, Heien ML, Seipel AT, Carelli RM, Wightman RM (2007) Coordinated accumbal dopamine release and neural activity drive goal-directed behavior. Neuron 54:237-244

Cohen MX, Heller AS, Ranganath C (2005) Functional connectivity with anterior cingulate and orbitofrontal cortices during decisionmaking. Brain Res Cogn Brain Res 23:61-70

Cromwell HC, Berridge KC (1993) Where does damage lead to enhanced food aversion: the ventral pallidum/substantia innominata or lateral hypothalamus? Brain Res 624:1-10

Cromwell HC, Hassani OK, Schultz W (2005) Relative reward processing in primate striatum. Exp Brain Res 162:520-525

Damasio AR (1999) The feeling of what happens: body and emotion in the making of consciousness, 1st edn. Harcourt Brace, CA

Damasio AR (2004) Emotions and feelings: a neurobiological perspective. In: Manstead ASR, Frijda N, Fischer A (eds) 
Feelings and emotions: the Amsterdam symposium. Cambridge University Press, Cambridge, UK, pp 49-57

Darwin C (1872) The expression of the emotions in man and animals. J. Murray, London

Davidson RJ, Sutton SK (1995) Affective neuroscience: the emergence of a discipline. Curr Opin Neurobiol 5:217-224

Davidson RJ, Scherer KR, Goldsmith HH (2003) Handbook of affective sciences. Oxford University Press, Oxford

Day JJ, Carelli RM (2007) The nucleus accumbens and Pavlovian reward learning. Neuroscientist 13:148-159

de Araujo IE, Kringelbach ML, Rolls ET, Hobden P (2003a) Representation of umami taste in the human brain. J Neurophysiol 90:313-319

de Araujo IE, Kringelbach ML, Rolls ET, McGlone F (2003b) Human cortical responses to water in the mouth, and the effects of thirst. J Neurophysiol 90:1865-1876

de Araujo IE, Rolls ET, Kringelbach ML, McGlone F, Phillips N (2003c) Taste-olfactory convergence, and the representation of the pleasantness of flavour, in the human brain. Eur J Neurosci 18:2059-2068

de Wit H, Enggasser JL, Richards JB (2002) Acute administration of D-amphetamine decreases impulsivity in healthy volunteers. Neuropsychopharmacology 27:813-825

Dehaene S, Kerszberg M, Changeux JP (1998) A neuronal model of a global workspace in effortful cognitive tasks. Proc Natl Acad Sci U S A 95:14529-14534

Di Chiara G, Bassareo V (2007) Reward system and addiction: what dopamine does and doesn't do. Curr Opin Pharmacol 7:69-76

Dickinson A, Balleine B (2002) The role of learning in the operation of motivational systems. In: Gallistel CR (ed) Stevens' handbook of experimental psychology: learning, motivation, and emotion. Wiley, New York, pp 497-534

Dickinson A, Balleine B (2008) Hedonics: the cognitive-motivational interface. In: Kringelbach ML, Berridge KC (eds) Pleasures of the brain. Oxford University Press, Oxford, UK (in press)

Dijksterhuis A, Bos MW, Nordgren LF, van Baaren RB (2006) On making the right choice: the deliberation-without-attention effect. Science 311:1005-1007

Evans AH, Pavese N, Lawrence AD, Tai YF, Appel S, Doder M, Brooks DJ, Lees AJ, Piccini P (2006) Compulsive drug use linked to sensitized ventral striatal dopamine transmission. Ann Neurol 59:852-858

Everitt BJ, Dickinson A, Robbins TW (2001) The neuropsychological basis of addictive behaviour. Brain Res Rev 36:129-138

Everitt BJ, Parkinson JA, Olmstead MC, Arroyo M, Robledo P, Robbins TW (1999) Associative processes in addiction and reward. The role of amygdala-ventral striatal subsystems. Ann N Y Acad Sci 877:412-438

Everitt BJ, Robbins TW (2005) Neural systems of reinforcement for drug addiction: from actions to habits to compulsion. Nat Neurosci 8:1481-1489

Feldman Barrett L, Wager TD (2006) The structure of emotion: evidence from neuroimaging studies. Curr Dir Psychol 15:79-83

Ferrari PF, van Erp AM, Tornatzky W, Miczek KA (2003) Accumbal dopamine and serotonin in anticipation of the next aggressive episode in rats. Eur J Neurosci 17:371-378

Fields HL, Hjelmstad GO, Margolis EB, Nicola SM (2007) Ventral tegmental area neurons in learned appetitive behavior and positive reinforcement. Annu Rev Neurosci 30:289-316

Finlayson G, King N, Blundell JE (2007) Is it possible to dissociate 'liking' and 'wanting' for foods in humans? A novel experimental procedure. Physiol Behav 90:36-42

Fischman MW, Foltin RW (1992) Self-administration of cocaine by humans: a laboratory perspective. In: Bock GR, Whelan J (eds) Cocaine: scientific and social dimensions (CIBA Foundation Symposium). Wiley, Chichester, UK, pp 165-180
Flagel SB, Watson SJ, Robinson TE, Akil H (2007) Individual differences in the propensity to approach signals vs goals promote different adaptations in the dopamine system of rats. Psychopharmacology (Berl) 191:599-607

Freud S, Riviere J (1930) Civilization and its discontents. J. Cape \& H. Smith, NY

Frijda NH (2007) The laws of emotion. L. Erlbaum, NJ

Frijda NH, Sundararajan L (2007) Emotion refinement: a theory inspired by Chinese poetics. Perspectives on Psychological Science 2:227-241

Ghitza UE, Fabbricatore AT, Prokopenko VF, West MO (2004) Differences between accumbens core and shell neurons exhibiting phasic firing patterns related to drug-seeking behavior during a discriminative-stimulus task. J Neurophysiol 92:1608-1614

Gilbert DT (2006) Stumbling on happiness. Alfred A. Knopf, NY

Gilbert DT, Wilson TD (2007) Prospection: experiencing the future. Science 317:1351-1354

Gottfried JA, O'Doherty J, Dolan RJ (2002) Appetitive and aversive olfactory learning in humans studied using event-related functional magnetic resonance imaging. J Neurosci 22:10829-10837

Gottfried J (2008) Neuroimaging of olfaction. In: Kringelbach ML, Berridge KC (eds) Pleasures of the brain. Oxford University Press, Oxford, UK (in press)

Grace AA (1991) Phasic versus tonic dopamine release and the modulation of dopamine system responsivity: a hypothesis for the etiology of schizophrenia. Neuroscience 41:1-24

Grace AA, Floresco SB, Goto Y, Lodge DJ (2007) Regulation of firing of dopaminergic neurons and control of goal-directed behaviors. Trends Neurosci 30:220-227

Green AL, Pereira EA, Aziz TZ (2008) Deep brain stimulation and pleasure. In: Kringelbach ML, Berridge KC (eds) Pleasures of the brain. Oxford University Press, Oxford, UK (in press)

Grill HJ, Norgren R (1978a) The taste reactivity test. I. Mimetic responses to gustatory stimuli in neurologically normal rats. Brain Res 143:263-79

Grill HJ, Norgren R (1978b) The taste reactivity test. II. Mimetic responses to gustatory stimuli in chronic thalamic and chronic decerebrate rats. Brain Res. 143:281-297

Gusnard DA, Raichle ME, Raichle ME (2001) Searching for a baseline: functional imaging and the resting human brain. Nat Rev Neurosci 2:685-694

Hart CL, Ward AS, Haney M, Foltin RW, Fischman MW (2001) Methamphetamine self-administration by humans. Psychopharmacology (Berl) 157:75-81

Heath RG (1972) Pleasure and brain activity in man. Deep and surface electroencephalograms during orgasm. J Nerv Ment Dis 154:3 18

Hernandez G, Hamdani S, Rajabi H, Conover K, Stewart J, Arvanitogiannis A, Shizgal P (2006) Prolonged rewarding stimulation of the rat medial forebrain bundle: neurochemical and behavioral consequences. Behav Neurosci 120:888-904

Higgins ET (2006) Value from hedonic experience and engagement. Psychol Rev 113:439-460

Hnasko TS, Sotak BN, Palmiter RD (2005) Morphine reward in dopamine-deficient mice. Nature 438:854-857

Hoebel BG (1988) Neuroscience and motivation: pathways and peptides that define motivational systems. In: Atkinson RC, Herrnstein RJ, Lindzey G, Luce RD (eds) Stevens' handbook of experimental psychology. Wiley, New York, pp 547-626

Hornak J, Bramham J, Rolls ET, Morris RG, O'Doherty J, Bullock PR, Polkey CE (2003) Changes in emotion after circumscribed surgical lesions of the orbitofrontal and cingulate cortices. Brain 126:1691-712

Horvitz JC (2000) Mesolimbocortical and nigrostriatal dopamine responses to salient non-reward events. Neuroscience 96: $651-656$ 
Hull CL (1951) Essentials of behavior. Yale University Press, New Haven

Hyman SE, Malenka RC, Nestler EJ (2006) Neural mechanisms of addiction: the role of reward-related learning and memory. Annu Rev Neurosci 29:565-598

Izard CE (2007) Basic emotions, natural kinds, emotion schemas, and a new paradigm. Perspectives on Psychological Science 2:260 280

Izquierdo A, Suda RK, Murray EA (2004) Bilateral orbital prefrontal cortex lesions in rhesus monkeys disrupt choices guided by both reward value and reward contingency. J Neurosci 24:7540-7548

Kahneman D, Diener E, Schwarz N (1999) Well-being: the foundations of hedonic psychology.. Russell Sage Foundation, New York, p xii, 593

Keedwell PA, Andrew C, Williams SC, Brammer MJ, Phillips ML (2005) The neural correlates of anhedonia in major depressive disorder. Biol Psychiatry 58:843-853

Kelley AE (2004) Memory and addiction: shared neural circuitry and molecular mechanisms. Neuron 44:161-179

Kelley AE, Bakshi VP, Haber SN, Steininger TL, Will MJ, Zhang M (2002) Opioid modulation of taste hedonics within the ventral striatum. Physiol Behav 76:365-377

Kelley AE, Baldo BA, Pratt WE, Will MJ (2005) Corticostriatalhypothalamic circuitry and food motivation: Integration of energy, action and reward. Physiol Behav 86:773-795

Knutson B, Adams CM, Fong GW, Hommer D (2001) Anticipation of increasing monetary reward selectively recruits nucleus accumbens. J Neurosci 21:U1-U5

Knutson B, Rick S, Wimmer GE, Prelec D, Loewenstein G (2007) Neural predictors of purchases. Neuron 53:147-156

Koob GF, Le Moal M (2006) Neurobiology of addiction. Academic Press, London

Kringelbach ML (2004) Food for thought: hedonic experience beyond homeostasis in the human brain. Neuroscience 126:807-819

Kringelbach ML (2005) The human orbitofrontal cortex: linking reward to hedonic experience. Nat Rev Neurosci 6:691-702

Kringelbach ML, Rolls ET (2004) The functional neuroanatomy of the human orbitofrontal cortex: evidence from neuroimaging and neuropsychology. Prog Neurobiol 72:341-372

Kringelbach ML, O’Doherty J, Rolls ET, Andrews C (2003) Activation of the human orbitofrontal cortex to a liquid food stimulus is correlated with its subjective pleasantness. Cereb Cortex 13:1064-1071

Kringelbach ML, de Araujo IE, Rolls ET (2004) Taste-related activity in the human dorsolateral prefrontal cortex. Neuroimage 21:781788

Kringelbach ML, Jenkinson N, Green AL, Owen SL, Hansen PC, Cornelissen PL, Holliday IE, Stein J, Aziz TZ (2007a) Deep brain stimulation for chronic pain investigated with magnetoencephalography. Neuroreport 18:223-228

Kringelbach ML, Jenkinson N, Owen SL, Aziz TZ (2007b) Translational principles of deep brain stimulation. Nat Rev Neurosci 8:623-635

Kringelbach ML (2008) The hedonic brain: a functional neuroanatomy of human pleasure. In: Kringelbach ML, Berridge KC (eds) Pleasures of the brain. Oxford University Press, Oxford, UK (in press)

Kringelbach ML, Berridge KC (2008) Pleasures of the brain. Oxford University Press, Oxford (in press)

Lamb RJ, Preston KL, Schindler CW, Meisch RA, Davis F, Katz JL, Henningfield JE, Goldberg SR (1991) The reinforcing and subjective effects of morphine in post-addicts: a dose-response study. J Pharmacol Exp Ther 259:1165-1173

Lawrence AD, Evans AH, Lees AJ (2003) Compulsive use of dopamine replacement therapy in Parkinson's disease: reward systems gone awry? Lancet Neurology 2:595-604
Le Magnen J (1967) Habits and food intake.. In: Code CF (ed) Alimentary canal (handbook of physiology (section 6)).. American Physiological Society, Washington, D.C.

LeDoux JE, Phelps EA (2000) Emotional networks in the brain. In: Lewis M, Haviland-Jones JM (eds) Handbook of emotions. Guilford, New York, pp 157-172

Leknes S, Tracey I (2008) Pleasure and pain: masters of mankind. In: Kringelbach ML, Berridge KC (eds) Pleasures of the brain. Oxford University Press, Oxford, UK (in press)

Levine AS, Kotz CM, Gosnell BA (2003) Sugars: hedonic aspects, neuroregulation, and energy balance.. Am J Clin Nutr 78:834S$842 \mathrm{~S}$

Leyton M, Boileau I, Benkelfat C, Diksic M, Baker G, Dagher A (2002) Amphetamine-Induced Increases in extracellular dopamine, drug wanting, and novelty seeking: a PET/[11C]raclopride study in healthy men. Neuropsychopharmacology 27:1027-1035

Leyton M, Casey KF, Delaney JS, Kolivakis T, Benkelfat C (2005) Cocaine craving, euphoria, and self-administration: a preliminary study of the effect of catecholamine precursor depletion. Behav Neurosci 119:1619-1627

Leyton M (2008) The neurobiology of desire: dopamine and the regulation of mood and motivational states in humans. In: Kringelbach ML, Berridge KC (eds) Pleasures of the brain. Oxford University Press, Oxford, UK (in press)

Mahler SV, Smith KS, Berridge KC (2007) Endocannabinoid hedonic hotspot for sensory pleasure: anandamide in nucleus accumbens shell enhances 'liking' of a sweet reward. Neuropsychopharmacology 32:2267-2278

Malenka RC, Bear MF (2004) LTP and LTD: an embarrassment of riches. Neuron 44:5-21

McClure SM, Berns GS, Montague PR (2003) Temporal prediction errors in a passive learning task activate human striatum. Neuron 38:339-346

Menon V, Levitin DJ (2005) The rewards of music listening: response and physiological connectivity of the mesolimbic system. Neuroimage 28:175-184

Merker B (2007) Consciousness without a cerebral cortex: a challenge for neuroscience and medicine. Behav Brain Sci 30:63-81 discussion 81-134

Mill JS, Crisp R, NetLibrary Inc. (1998) Utilitarianism Oxford philosophical texts.. Oxford University Press, Oxford, p vii, p. 157

Mitterschiffthaler MT, Kumari V, Malhi GS, Brown RG, Giampietro VP, Brammer MJ, Suckling J, Poon L, Simmons A, Andrew C, Sharma T (2003) Neural response to pleasant stimuli in anhedonia: an fMRI study. Neuroreport 14:177-182

Nesse RM (2002) Evolutionary biology: a basic science for psychiatry. World Psychiatry 1:7-9

Nicola SM, Taha SA, Kim SW, Fields HL (2005) Nucleus accumbens dopamine release is necessary and sufficient to promote the behavioral response to reward-predictive cues. Neuroscience 135:1025-1033

Niv Y, Daw ND, Joel D, Dayan P (2007) Tonic dopamine: opportunity costs and the control of response vigor. Psychopharmacology (Berl) 191:507-520

O'Doherty J, Rolls ET, Francis S, Bowtell R, McGlone F, Kobal G, Renner B, Ahne G (2000) Sensory-specific satiety-related olfactory activation of the human orbitofrontal cortex. Neuroreport 11:399-403

O’Doherty J, Kringelbach ML, Rolls ET, Hornak J, Andrews C (2001) Abstract reward and punishment representations in the human orbitofrontal cortex. Nat Neurosci 4:95-102

O’Doherty JP, Buchanan TW, Seymour B, Dolan RJ (2006) Predictive neural coding of reward preference involves dissociable responses in human ventral midbrain and ventral striatum. Neuron 49:157-166 
O’Doherty JP, Deichmann R, Critchley HD, Dolan RJ (2002) Neural responses during anticipation of a primary taste reward. Neuron $33: 815-826$

Olds J (1956) Pleasure centers in the brain. Sci Am 195:105-116

Olds J (1961) Differential Effects of Drives and Drugs on SelfStimulation at Different Brain Sites. University of Texas Press, Austin, TX

Olds J, Milner P (1954) Positive reinforcement produced by electrical stimulation of septal area and other regions of rat brain. J Comp Physiol Psychol 47:419-427

Palmiter RD (2007) Is dopamine a physiologically relevant mediator of feeding behavior? Trends Neurosci 30:375-381

Panksepp J (1991) Affective Neuroscience: A Conceptual Framework for the Study of Emotions. In: Strongman K (ed) International reviews of studies in emotions. Wiley, Chichester, pp 59-99

Panksepp J (1998) Affective Neuroscience: the Foundations of Human and Animal Emotions. Oxford University Press, Oxford

Panksepp J (2005) Affective consciousness: core emotional feelings in animals and humans. Conscious Cogn 14:30-80

Panksepp J (2007) Neurologizing the psychology of affects: how appraisal-based constructivism and basic emotion theory can coexist. Perspectives on Psychological Science 2:281-296

Parkinson JA, Olmstead MC, Burns LH, Robbins TW, Everitt BJ (1999) Dissociation in effects of lesions of the nucleus accumbens core and shell on appetitive Pavlovian approach behavior and the potentiation of conditioned reinforcement and locomotor activity by D-amphetamine. J Neurosci 19:2401-2411

Pears A, Parkinson JA, Hopewell L, Everitt BJ, Roberts AC (2003) Lesions of the orbitofrontal but not medial prefrontal cortex disrupt conditioned reinforcement in primates. J Neurosci 23:11189-11201

Peciña S, Berridge KC (2005) Hedonic hot spot in nucleus accumbens shell: where do mu-opioids cause increased hedonic impact of sweetness? J Neurosci 25:11777-11786

Peciña S, Cagniard B, Berridge KC, Aldridge JW, Zhuang X (2003) Hyperdopaminergic mutant mice have higher "wanting" but not "liking" for sweet rewards. J Neurosci 23:9395-9402

Peciña S, Smith KS, Berridge KC (2006) Hedonic hot spots in the brain. Neuroscientist 12:500-511

Pelchat ML, Johnson A, Chan R, Valdez J, Ragland JD (2004) Images of desire: food-craving activation during. fMRI 23:1486-1493

Pessiglione M, Seymour B, Flandin G, Dolan RJ, Frith CD (2006) Dopamine-dependent prediction errors underpin reward-seeking behaviour in humans. Nature 442:1042-1045

Pessiglione M, Schmidt L, Draganski B, Kalisch R, Lau H, Dolan R, Frith $C$ (2007) How the brain translates money into force: a neuroimaging study of subliminal motivation. Science 316:904906

Petrovic P (2008) Placebo anagesia and the brain. In: Kringelbach ML, Berridge KC (eds) Pleasures of the brain. Oxford University Press, Oxford, UK (in press)

Phillips PE, Stuber GD, Heien ML, Wightman RM, Carelli RM (2003) Subsecond dopamine release promotes cocaine seeking. Nature 422:614-618

Pickens CL, Saddoris MP, Setlow B, Gallagher M, Holland PC, Schoenbaum G (2003) Different roles for orbitofrontal cortex and basolateral amygdala in a reinforcer devaluation task. J Neurosci 23:11078-11084

Portenoy RK, Jarden JO, Sidtis JJ, Lipton RB, Foley KM, Rottenberg DA (1986) Compulsive thalamic self-stimulation: a case with metabolic, electrophysiologic and behavioral correlates. Pain 27:277-290

Rahman S, Robbins TW, Sahakian BJ (1999) Comparative cognitive neuropsychological studies of frontal lobe function: implications for therapeutic strategies in frontal variant frontotemporal dementia. Dement Geriatr Cogn Disord 10(Suppl 1):15-28
Redgrave P, Gurney K (2006) The short-latency dopamine signal: a role in discovering novel actions? Nat Rev Neurosci 7:967-975

Reynolds SM, Berridge KC (2002) Positive and negative motivation in nucleus accumbens shell: Bivalent rostrocaudal gradients for GABA-elicited eating, taste "liking"/“disliking" reactions, place preference/avoidance, and fear. J Neurosci 22:7308-7320

Robbins TW, Everitt BJ (2002) Limbic-striatal memory systems and drug addiction. Neurobiol Learn Mem 78:625-636

Robbins TW, Everitt BJ (2007) A role for mesencephalic dopamine in activation: commentary on Berridge (2006). Psychopharmacology (Berl) 191:433-437

Robinson S, Sandstrom SM, Denenberg VH, Palmiter RD (2005) Distinguishing whether dopamine regulates liking, wanting, and/ or learning about rewards. Behav Neurosci 119:5-15

Robinson TE, Berridge KC (1993) The neural basis of drug craving: an incentive-sensitization theory of addiction. Brain Res Rev 18:247-291

Robinson TE, Berridge KC (2003) Addiction. Annu Rev Psychol $54: 25-53$

Roitman MF, Stuber GD, Phillips PEM, Wightman RM, Carelli RM (2004) Dopamine operates as a subsecond modulator of food seeking. J Neurosci 24:1265-1271

Roitman MF, Wheeler RA, Carelli RM (2005) Nucleus accumbens neurons are innately tuned for rewarding and aversive taste stimuli, encode their predictors, and are linked to motor output. Neuron 45:587-597

Rolls BJ, Rolls ET, Rowe EA, Sweeney K (1981) Sensory specific satiety in man. Physiol. Behav. 27:137-142

Rolls ET (2005) Emotion explained. Oxford University Press, Oxford

Rolls ET, Kringelbach ML, de Araujo IE (2003) Different representations of pleasant and unpleasant odours in the human brain. Eur J Neurosci 18:695-703

Rozin P (1999) Preadaptation and the puzzles and properties of pleasure. In: Kahneman D, Diener E, Schwarz N (eds) Wellbeing: the foundations of hedonic psychology. Russell Sage Foundation, New York, pp 109-133

Rudebeck PH, Walton ME, Smyth AN, Bannerman DM, Rushworth MF (2006) Separate neural pathways process different decision costs. Nat Neurosci 9:1161-1168

Ryle G (1954) Pleasure. Proceedings of the Aristotelian Society 28:135-146

Salamone JD (1994) The involvement of nucleus accumbens dopamine in appetitive and aversive motivation. Behav Brain Res 61:117-133

Salamone JD, Correa M, Farrar A, Mingote SM (2007) Effort-related functions of nucleus accumbens dopamine and associated forebrain circuits. Psychopharmacology (Berl) 191:461-482

Schallert T, Whishaw IQ (1978) Two types of aphagia and two types of sensorimotor impairment after lateral hypothalamic lesions: observations in normal weight, dieted, and fattened rats. J Comp Physiol Psychol 92:720-741

Schoenbaum G, Shaham Y (2007) The role of orbitofrontal cortex in drug addiction: a review of preclinical studies. Biol Psychiatry 63:256-262

Schoenbaum G, Roesch MR, Stalnaker TA (2006) Orbitofrontal cortex, decision-making and drug addiction. Trends Neurosci 29:116-124

Schooler JW, Mauss IB (2008) To be happy and to know it: the experience and meta-awareness of pleasure. In: Kringelbach ML, Berridge KC (eds) Pleasures of the brain. Oxford University Press, Oxford, UK (in press)

Schulkin J (2004) Allostasis, homeostasis, and the costs of physiological adaptation. Cambridge University Press, Cambridge

Schultz W (1997) Dopamine neurons and their role in reward mechanisms. Curr Opin Neurobiol 7:191-977

Schultz W (2006) Behavioral theories and the neurophysiology of reward, Annu Rev Psychol 57:87-115 
Schultz W (2007) Multiple dopamine functions at different time courses. Annu Rev Neurosci 30:259-288

Schultz W, Dayan P, Montague PR (1997) A neural substrate of prediction and reward. Science 275:1593-1599

Scott DJ, Heitzeg MM, Koeppe RA, Stohler CS, Zubieta JK (2006) Variations in the human pain stress experience mediated by ventral and dorsal basal ganglia dopamine activity. J Neurosci 26:10789-10795

Scott DJ, Stohler CS, Egnatuk CM, Wang H, Koeppe RA, Zubieta J-K (2007) Individual differences in reward responding explain placebo-induced expectations and effects. Neuron 55:325-336

Setlow B, Holland PC, Gallagher M (2002) Disconnection of the basolateral amygdala complex and nucleus accumbens impairs appetitive Pavlovian second-order conditioned responses. Behav Neurosci 116:267-275

Shewmon DA, Holmes GL, Byrne PA (1999) Consciousness in congenitally decorticate children: developmental vegetative state as self-fulfilling prophecy. Dev Med Child Neurol 41:364-74

Shizgal P, Arvanitogiannis A (2003) Neuroscience. Gambling on dopamine. Science 299:1856-1858

Shizgal P, Fulton S, Woodside B (2001) Brain reward circuitry and the regulation of energy balance. Int J Obes 25:S17-S21

Skinner BF (1938) The behavior of organisms: an experimental analysis. D. Appleton-Century, NY

Small D, Veldhuizen M (2008) Human crossmodal studies of taste and smell. In: Kringelbach ML, Berridge KC (eds) Pleasures of the brain. Oxford University Press, Oxford, UK (in press)

Small DM, Zatorre RJ, Dagher A, Evans AC, Jones-Gotman M (2001) Changes in brain activity related to eating chocolate-from pleasure to aversion. Brain 124:1720-1733

Small DM, Gregory MD, Mak YE, Gitelman D, Mesulam MM, Parrish T (2003) Dissociation of neural representation of intensity and affective valuation in human gustation. Neuron 39:701-711

Smith KS, Berridge KC (2005) The ventral pallidum and hedonic reward: neurochemical maps of sucrose "liking" and food intake. J Neurosci 25:8637-8649

Smith KS, Berridge KC (2007) Opioid limbic circuit for reward: interaction between hedonic hotspots of nucleus accumbens and ventral pallidum. J Neurosci 27:1594-605

Smith KS, Mahler SV, Pecina S, Berridge KC (2008) Hedonic hotspots: generating sensory pleasure in the brain. In: Kringelbach M, Berridge KC (eds) Pleasures of the brain. Oxford University Press, Oxford, UK (in press)

Steiner JE (1973) The gustofacial response: observation on normal and anencephalic newborn infants. Symp Oral Sens Percept 4:254-278

Steiner JE, Glaser D, Hawilo ME, Berridge KC (2001) Comparative expression of hedonic impact: Affective reactions to taste by human infants and other primates. Neurosci Biobehav Rev 25:53-74

Stellar JR, Brooks FH, Mills LE (1979) Approach and withdrawal analysis of the effects of hypothalamic stimulation and lesions in rats. J Comp Physiol Psychol 93:446-466

Szczypka MS, Kwok K, Brot MD, Marck BT, Matsumoto AM, Donahue BA, Palmiter RD (2001) Dopamine production in the caudate putamen restores feeding in dopamine-deficient mice. Neuron 30:819-28

Taha SA, Fields HL (2006) Inhibitions of nucleus accumbens neurons encode a gating signal for reward-directed behavior. J Neurosci 26:217-222

Teitelbaum P, Epstein AN (1962) The lateral hypothalamic syndrome: recovery of feeding and drinking after lateral hypothalamic lesions. Psychol Rev 69:74-90

Tindell AJ, Berridge KC, Aldridge JW (2004) Ventral pallidal representation of Pavlovian cues and reward: population and rate codes. J Neurosci 24:1058-1069

Tindell AJ, Berridge KC, Zhang J, Peciña S, Aldridge JW (2005) Ventral pallidal neurons code incentive motivation: amplification by mesolimbic sensitization and amphetamine. Eur $\mathrm{J}$ Neurosci 22:2617-2634

Tindell AJ, Smith KS, Pecina S, Berridge KC, Aldridge JW (2006) Ventral pallidum firing codes hedonic reward: when a bad taste turns good. J Neurophysiol 96:2399-2409

Tobler PN, O'Doherty JP, Dolan RJ, Schultz W (2005) Human neural learning depends on reward prediction errors in the blocking paradigm. J Neurophysiol 95:301-310

Tucker DM, Luu P, Pribram KH (1995) Social and emotional selfregulation. Ann N Y Acad Sci 769:213-239

Uslaner JM, Acerbo MJ, Jones SA, Robinson TE (2006) The attribution of incentive salience to a stimulus that signals an intravenous injection of cocaine. Behav Brain Res 169:320-324

Valenstein ES (1986) Great and desperate cures: the rise and decline of psychosurgery and other radical treatments for mental illness. Basic Books, NY

Valenstein ES, Cox VC, Kakolewski JW (1970) Reexamination of the role of the hypothalamus in motivation. Psychol Rev 77:16-31

Vanderschuren LJ, Everitt BJ (2005) Behavioral and neural mechanisms of compulsive drug seeking. Eur $\mathrm{J}$ Pharmacol 526:77-88

Vezina P (2004) Sensitization of midbrain dopamine neuron reactivity and the self-administration of psychomotor stimulant drugs. Neurosci Biobehav Rev 27:827-839

Volkow ND, Wang GJ, Fowler JS, Logan J, Jayne M, Franceschi D, Wong C, Gatley SJ, Gifford AN, Ding YS, Pappas N (2002) "Nonhedonic" food motivation in humans involves dopamine in the dorsal striatum and methylphenidate amplifies this effect. Synapse 44:175-180

Volkow ND, Wang GJ, Telang F, Fowler JS, Logan J, Childress AR, Jayne M, Ma Y, Wong C (2006) Cocaine cues and dopamine in dorsal striatum: mechanism of craving in cocaine addiction. $\mathrm{J}$ Neurosci 26:6583-6588

Wager TD, Rilling JK, Smith EE, Sokolik A, Casey KL, Davidson RJ, Kosslyn SM, Rose RM, Cohen JD (2004) Placebo-induced changes in FMRI in the anticipation and experience of pain. Science 303:1162-1167

Wallis JD (2007) Orbitofrontal cortex and its contribution to decisionmaking. Annu Rev Neurosci 30:31-56

Wallis JD, Miller EK (2003) Neuronal activity in primate dorsolateral and orbital prefrontal cortex during performance of a reward preference task. Eur J Neurosci 18:2069-2081

Wan X, Peoples LL (2006) Firing patterns of accumbal neurons during a Pavlovian-conditioned approach task. J Neurophysiol 96:652-660

Wang GJ, Volkow ND, Telang F, Jayne M, Ma J, Rao M, Zhu W, Wong CT, Pappas NR, Geliebter A, Fowler JS (2004) Exposure to appetitive food stimuli markedly activates the human brain. Neuroimage 21:1790-1797

Watson KK, Matthews BJ, Allman JM (2006) Brain activation during sight gags and language-dependent humor. Cereb Cortex 17:314324

Whalen PJ, Rauch SL, Etcoff NL, McInerney SC, Lee MB, Jenike MA (1998) Masked presentations of emotional facial expressions modulate amygdala activity without explicit knowledge. J Neurosci 18:411-418

Wheeler RA, Carelli RM (2006) The neuroscience of pleasure: focus on ventral pallidum firing codes hedonic reward: when a bad taste turns good. J Neurophysiol 96:2399-2409

Whishaw IQ, Kornelsen RA (1993) Two types of motivation revealed by ibotenic acid nucleus accumbens lesions: dissociation of food carrying and hoarding and the role of primary and incentive motivation. Behav Brain Res 55:283-295

Wiers RW, Stacy AW (2006) Handbook of implicit cognition and addiction. Sage, Thousand Oaks, California, p 550

Wiers RW, Bartholow BD, van den Wildenberg E, Thush C, Engels RC, Sher KJ, Grenard J, Ames SL, Stacy AW (2007) Automatic 
and controlled processes and the development of addictive behaviors in adolescents: a review and a model. Pharmacol Biochem Behav 86:263-283

Wightman RM, Robinson DL (2002) Transient changes in mesolimbic dopamine and their association with 'reward'. J Neurochem 82:721-735

Wightman RM, Heien ML, Wassum KM, Sombers LA, Aragona BJ, Khan AS, Ariansen JL, Cheer JF, Phillips PE, Carelli RM (2007) Dopamine release is heterogeneous within microenvironments of the rat nucleus accumbens. Eur J Neurosci 26:20462054
Winkielman P, Berridge KC, Wilbarger JL (2005) Unconscious affective reactions to masked happy versus angry faces influence consumption behavior and judgments of value. Personality and Social Psychology Bulletin 31:121-135

Wise RA (2006) Role of brain dopamine in food reward and reinforcement. Philos Trans R Soc Lond B Biol Sci 361:1149-1158

Wyvell CL, Berridge KC (2001) Incentive-sensitization by previous amphetamine exposure: Increased cue-triggered 'wanting' for sucrose reward. J Neurosci 21:7831-7840

Yin HH, Zhuang X, Balleine BW (2006) Instrumental learning in hyperdopaminergic mice. Neurobiol Learn Mem 85:283-288 